\title{
MARILENA NAKAgUMA
}

\section{Estudo da etiologia do hipopituitarismo congênito por sequenciamento paralelo em larga escala de um painel gênico}

\author{
Tese apresentada à Faculdade de Medicina da \\ Universidade de São Paulo para obtenção do título \\ de Doutor em Ciências \\ Programa de Endocrinologia \\ Orientador: Prof. Dr. Ivo Jorge Prado Arnhold \\ Co orientador: Prof. Dr. Alexander Augusto de \\ Lima Jorge
}

(Versõa corrigida. resolução CoPGr 5890 de 20 de dezembro de 2010)

São Paulo 
Dados Internacionais de Catalogação na Publicação (CIP)

Preparada pela Biblioteca da

Faculdade de Medicina da Universidade de São Paulo

Creprodução autorizada pelo autor

Nakaguma, Marilena

Estudo da etiologia do hipopituitarismo

congênito por sequenciamento paralelo em larga

escala de um painel gênico / Marilena Nakaguma. São Paulo, 2019.

Tese(doutorado)--Faculdade de Medicina da Universidade de São Paulo.

Programa de Endocrinologia.

Orientador: Ivo Jorge Prado Arnhold.

Coorientador: Alexander Aaugusto de Lima Jorge.

Descritores: 1.Hipopituitarismo 2.Sequenciamento de nucleotídeos em larga escala 3.Mutação 4.Nanismo hipofisário 5.Anormalidades congênitas 6.Sistema hipotálamo-hipofisário

$\mathrm{USP} / \mathrm{FM} / \mathrm{DBD}-240 / 19$

Responsável: Erinalva da Conceição Batista, CRB-8 6755 
Este trabalho foi realizado na Unidade de Endocrinologia do Desenvolvimento e no Laboratório de Hormônios e Genética Molecular LIM/42 da Disciplina de Endocrinologia e Metabologia do Hospital das Clínicas da Universidade de São Paulo, com apoio da Fundação de Amparo à Pesquisa do Estado de São Paulo (FAPESP): Projeto temático 13/03236-5 e Bolsa de Doutorado CAPES 
“Só um sentido de invenção e uma necessidade intensa de criar levam o homem a revoltar-se, a descobrir e a descobrirse com lucidez"

Pablo Picasso 


\section{Agradecimentos}

A meu orientador Prof. Ivo Jorge Prado Arnhold, por ter confiado em mim e ter me recebido para realização deste estudo. Seus ensinamentos e orientações foram essenciais não só ao desenvolvimento desta pesquisa, como também para meu crescimento pessoal nesse período. Seu conhecimento e profissionalismo servem de exemplo que levarei para a vida.

Ao Prof. Alexander Augusto de Lima Jorge, meu co orientador, agradeço pelos muitos ensinamentos, dedicação e paciência.

Agradecimento especial a Fernanda Correa, pesquisadora entusiasmada, incentivadora e amiga, que me ensinou sobre a pesquisa e seus valores, sobretudo.

Agradeço aos colegas e à equipe técnica do LIM 42 e LIM 25 pelo companheirismo, dedicação e profissionalismo. Em especial, a Elisangela Quedas, Lucas Santos, Betty Urtremary e Graça, pela atenção e carinho ao longo desta trajetória. Obrigada também a Mariana Funari, pelo sequenciamento - etapa delicada e fundamental do projeto e por todo apoio e ajuda, e a Antonio Lerário pela análise de bioinformática.

A Profa. Berenice B. de Mendonça e a Profa. Ana Claudia Latrônico que são modelos de pesquisadora e liderança.

A Luciani Carvalho, Anna Flávia, Isabela Biscotto, João Madeira e Nathalia Ferreira, do grupo do hipopituitarismo, e a Alexsandra Malaquias, Edoarda Vasco, Gabriela Vasques, Renata Scalco, Thais Lima, Thais Kataoka, do grupo de crescimento, pelo convívio, companhia e constante apoio. Tenho certeza que nossas amizades não ficarão restritas ao ambulatório. Em especial, às minhas amigas queridas Cybelle Rejane Marques Silveira, Cristiane Gruetzmacher, Mirela Costa de Miranda, 
Priscila Salles e Tatiana Pelaes que desde o início estiveram ao meu lado, nos melhores momentos e nos mais difíceis.

A todos os professores e membros da equipe do curso de Pós-Graduação em Endocrinologia da Faculdade de Medicina da Universidade de São Paulo (FMUSP), pelo profundo conhecimento e profissionalismo transmitido durante esse período. Agradeço também a nossos pacientes, que constituem a fonte de nossos estudos e que sempre trazem ensinamentos e inspirações para nossas vidas. Não é possível mencionar individualmente aqui todos que me ajudaram, de maneira direta ou indireta, mas nestes parágrafos registro minha gratidão aos que estiveram envolvidos no desenvolvimento de meu trabalho.

Agradecimento aos colaboradores Ricardo Perez, Mirta Miras e à querida amiga e entusiasta de pesquisa Martha Katherine P Huayllas.

Quero agradecer também a minha família, em especial, a meu pai Roberto, a minha mãe Eliza e a meu irmão Marcos que nunca deixaram de iluminar um caminho que tenha me parecido escuro. Obrigada pelo amor e apoio incondicionais durante o desenvolvimento de meu doutorado e também por toda a vida.

E, por fim, a meu querido marido Jackson que jamais deixou de me apoiar e incentivar. 


\section{Normalização}

Esta tese está de acordo com as seguintes normas, em vigor no momento desta publicação.

Referências: adaptado de International Committee of Medical Jornal Editors (Vancouver).

Universidade de São Paulo. Faculdade de Medicina. Divisão de Biblioteca e Documentação. Guia de Apresentação de dissertações, teses e monografias. Elaborado por Anneliese Carneiro da Cunha; Maria Júlia de A. L. Freddi; Maria F. Crestana; Marinalva de Souza Aragão; Suely Campos Cardoso; Valéria Vilhena. Зa. ed. São Paulo: Divisão de Biblioteca e Documentação, 2011.

Abreviatura dos títulos de periódicos de acordo com List of Journals Indexed in Index Medicus. 


\section{Sumário}

Lista de Abreviaturas e Símbolos

Lista de Genes e Proteínas

Lista de Figuras

Lista de Tabelas

Lista de anexos

Resumo

Abstract

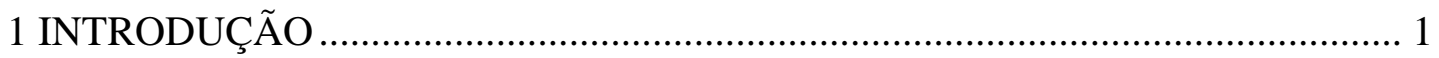

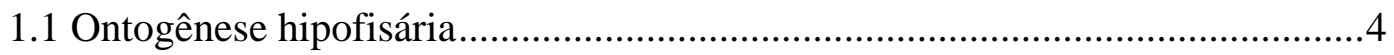

1.1.1 Defeitos na embriogênese da região hipotálamo-hipofisária.................6

1.1.2 Defeitos na diferenciação das células hipofisárias ................................8

1.2 Regulação da síntese e secreção de GH ............................................................9

1.2.1 Defeitos na síntese e secreção de GH .................................................9

1.3 O uso da técnica de SPLE na identificação de genes associados à DGH congênita.............................................................................................11

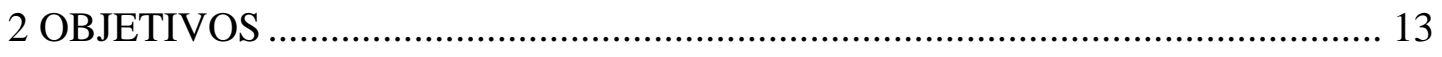

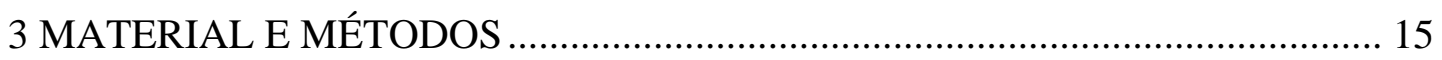

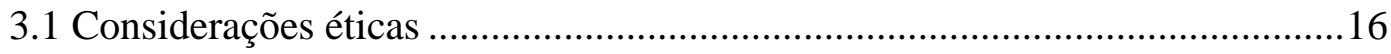

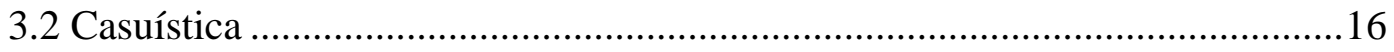

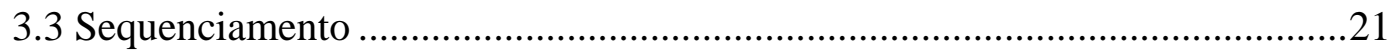

3.3.1 Extração do DNA genômico...............................................................21

3.3.2 Desenho de sondas de captura do painel .............................................21

3.3.3 Genotipagem por sequenciamento de nova geração............................22

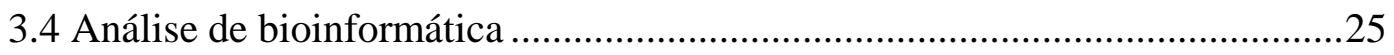

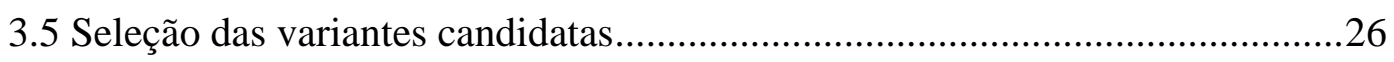

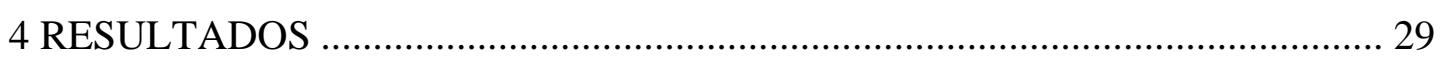

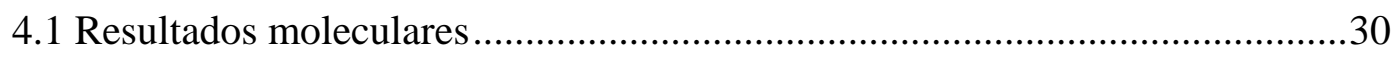

4.2 Fenótipo dos pacientes com variantes patogênicas.........................................33

4.2.1 Paciente com a variante GLI2 c.1681G>T ........................................33 
4.2.2 Paciente com a variante OTX2 c.295C > T .34

4.2.3 Paciente com variantes PROP1 [c.301_302del];[ c.109+1G>A] ........36

4.2.4 Pacientes com variantes $G H R H R[$ c.57+1G $>$ A]; [ c.57+1G>A] e GHRHR [c.820_821insC];[ c.820_821insC] .............................................38

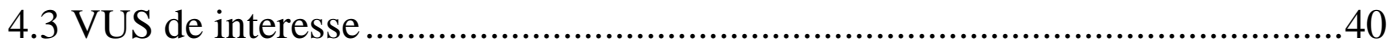

4.3.1 Pacientes com a variante GHSR c.545T>C .......................................40

4.3.2 Paciente com a variante TGIF1 c.82T> C ..........................................43

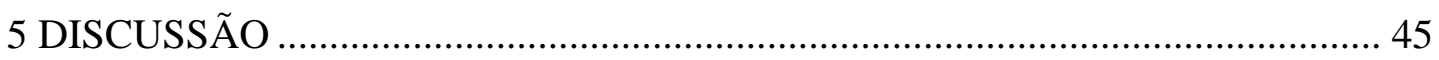

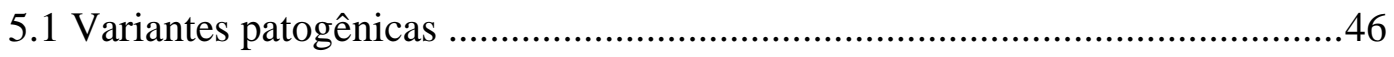

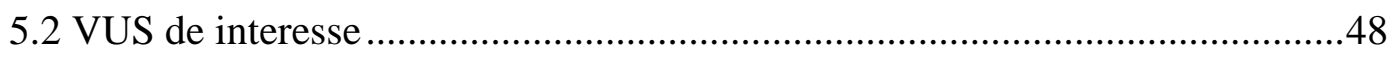

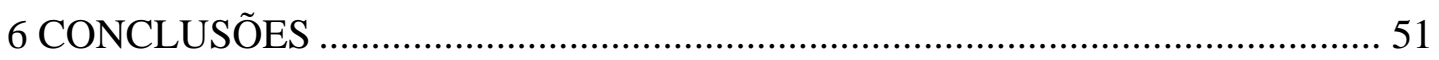

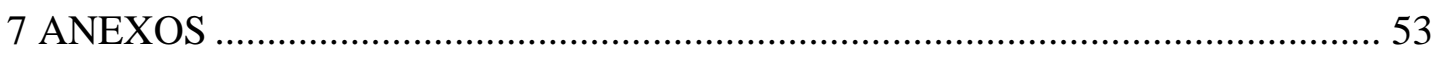

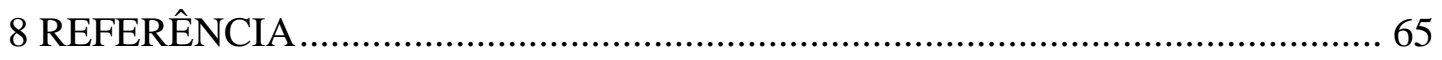




\section{Listas}

\section{ABREVIATURAS E SÍMBOLOS}

\begin{tabular}{|c|c|}
\hline ABraOM & Brazilian genomic variants \\
\hline AC & allele counting (número de alelos encontrados) \\
\hline ACMG/AMP & $\begin{array}{l}\text { Colégio Americano de Genética Médica e Associação de Patologia } \\
\text { Molecular }\end{array}$ \\
\hline ACTH & adrenocorticotropic hormone (hormônio adenocorticotrófico) \\
\hline $\mathrm{ADH}$ & hormônio antidiurético \\
\hline BWA & Burrows-Wheeler Aligner (programa de bioinformática) \\
\hline CADD & Annotation Dependent Depletion \\
\hline CNVs & Copy Number Variations (variação do número de cópias) \\
\hline CONTRA & $\begin{array}{l}\text { Copy Number Analysis for Targeted Resequencing (análise do número de } \\
\text { cópias para sequenciamento direcionado) }\end{array}$ \\
\hline $\mathrm{CtBP}$ & C-terminal-binding protein 1 \\
\hline DGH & deficiência do hormônio de crescimento \\
\hline DHEAS & sulfato de deidroepiandrosterona \\
\hline DHHM & deficiência hipotálamo-hipofisária múltipla \\
\hline DIGH & deficiência isolada de hormônio de crescimento \\
\hline DNA & ácido desoxirribonucleico \\
\hline DSO & displasia septo-óptica \\
\hline ESP-6500 & Exome Sequencing Project, do National Heart, Lung, and Blood Institute \\
\hline ExAC & Exome Aggregetion Consortium (banco de dados populacional) \\
\hline FATHMM & $\begin{array}{l}\text { Functional Analysis through Hidden Markov Models (ferramenta de } \\
\text { predição in silico) }\end{array}$ \\
\hline FSH & follicle-stimulating hormone (hormônio folículo-estimulante) \\
\hline GERP & genomic evolutionary rate profiling \\
\hline GH & growth hormone (hormônio do crescimento) \\
\hline HC & hipopituitarismo congênito \\
\hline HGMD & The Human Gene Mutation Database \\
\hline HPE & Holoprosencefalia \\
\hline
\end{tabular}


IAMSPE

IGF-1

IGFBP-3

IGV

IO

ITT

LH

MAF

$\mathrm{NH}$

NHE

NHT

OMIM

PCR

PolyPhen

PRL

PROVEAN

PSIS

ACCD

RM

RNA

RXR

SIFT

SNC

SNPs

SPLE

SST

TRH

TSH

VC

VCF

VEST3

VR

VUS

WES
Instituto de Assistência Médica ao Servidor Público Estadual

insulin like growth factor 1

insulin-like growth factor binding protein 3

Integrative Genomics Viewer (visualizador integrativo de genômica)

idade óssea

teste de tolerância à insulina

luteinizing hormone (hormônio luteinizante)

minor allele frequence (frequência do alelo menos frequente)

neuro-hipófise

neuro-hipófise ectópica

neuro-hipófise tópica

Online Mendelian Inheritance in Man (base de dados que cataloga doenças genéticas)

reação em cadeia da polimerase

Polymorphism Phenotyping (ferramenta de predição in silico)

Prolactina

Protein Variation Effect Analyzer (ferramenta de predição in silico)

Pituitary stalk interruption syndrome (síndrome da interrupção de haste)

Atraso constitucional do crescimento e desenvolvimento

ressonância magnética

Ácido ribonucleico

receptor de ácido retinóico

Sorting Intolerant from Tolerant Human Protein (ferramenta de predição in silico)

sistema nervoso central

single nucleotide polymorphisms (polimorfismo de nucleotídeo único)

sequenciamento paralelo em larga escala

Somatostatina

thyrotropin-releasing hormone (hormônio liberador de tireotropina)

thyroid stimulating hormone (hormônio tireoestimulante)

velocidade de crescimento

Variant Call Format

Variant Effect Scoring Tool

valor de referência

Variant of Uncertain Significance (Variante de Significado Incerto)

Whole Exome Sequencing (sequenciamento exômico) 


\section{GENES E PROTEÍNAS}

\begin{tabular}{|c|c|}
\hline ARNT2 & aryl hydrocarbon receptor nuclear translocator 2 \\
\hline$D M X L 2$ & Rabconnectin \\
\hline FGF8 & fibroblast growth factor 8 \\
\hline FGFR1 & fibroblast growth factor receptor 1 \\
\hline GH1 & growth hormone 1 \\
\hline GHRH & growth hormone-releasing hormone \\
\hline GHRHR & growth hormone-releasing hormone receptor \\
\hline GHSR & growth hormone secretagogue receptor \\
\hline GLI2 & gli-kruppel family member 2 \\
\hline GPR161 & g protein-coupled receptor 161 \\
\hline HES1 & hairy/enhancer of split \\
\hline HESX1 & homeobox gene expressed in es cells \\
\hline HHIP & hedgehog-interacting protein \\
\hline IGSF1 & immunoglobulin superfamily, member 1 \\
\hline KAL1 & kal1 gene \\
\hline LHX3 & lim homeobox gene 3 \\
\hline LHX4 & lim homeobox gene 4 \\
\hline NEUROD4 & neurogenic differentiation 4 \\
\hline OTX2 & orthodenticle, drosophila, homolog of, 2 \\
\hline PITX2 & paired-like homeodomain transcription factor 2 \\
\hline POU1F1 & pituitary-specific transcription factor 1 \\
\hline PROKR2 & prokineticin receptor 2 \\
\hline PROP1 & prop paired-like homeobox 1 \\
\hline RNPC3 & RNA-binding region-containing protein 3 \\
\hline $\mathrm{SHH}$ & sonic hedgehog \\
\hline SOX2 & sry-box 2 \\
\hline SOX3 & sry-box 3 \\
\hline PSIS & Pituitary Stalk Interruption Syndrome (Síndrome da Interrupção da Haste) \\
\hline TGIF1 & transforming growth factor-beta-induced factor \\
\hline$T G F \beta$ & transforming growth factor beta \\
\hline
\end{tabular}


FIGURAS

Figura 1 - Desenvolvimento do eixo hipotálamo-hipofisário ................................ 5

Figura 2 - Diagnóstico da deficiência do hormônio de crescimento .................... 17

Figura 3 - $\quad$ Pacientes selecionados para estudo ..................................................... 19

Figura 4 - $\quad$ Sequenciamento paralelo em larga escala .......................................... 24

Figura 5 - Visualização das variantes encontradas no gene $P R O P 1$ no programa IGV

Figura 6 - Eletroferograma do sequenciamento por Sanger das variantes no gene PROP1

Figura 7 - Visualização das variantes encontradas no gene GLI2 no programa IGV (Integrative Genomics Viewer) 42 
TABELAS

Tabela 1 - Genes relacionados a defeitos na embriogênese da região hipotálamohipofisária, fenótipo e modelo de herança dos pacientes com hipopituitarismo congênito 7

Tabela 2 - Caracterização dos pacientes selecionados para estudo...................... 19

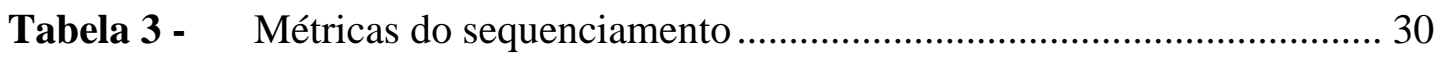

Tabela 4 - Variantes patogênicas identificadas pelo painel de genes em uma coorte de 117 pacientes com hipopituitarismo congênito 32

Tabela 5 - Características clínicas dos pacientes com variantes patogênicas ..... 39

Tabela 6- Variantes de significado incerto de interesse identificadas pelo painel de genes em uma coorte de 117 pacientes com hipopituitarismo congênito 


\section{ANEXOS}

Anexo 1 - 16 variantes de significado incerto, identificadas pelo Painel de Genes em uma coorte de 117 pacientes com hipopituitarismo congênito 54

Anexo 2 - Critérios utilizados pela ACMG/AMP - Colégio Americano de Genética Médica e pela Associação de Patologia Molecular - para classificação das variantes encontradas . 56

Anexo 3 - "Genetic diagnosis of congenital hypopituitarism by a target gene panel: novel pathogenic variants in GLI2, OTX2 and GHRHR”.. 59 


\section{Resumo}

Nakaguma M. Estudo da etiologia do hipopituitarismo congênito pelo sequenciamento paralelo em larga escala de um painel gênico [tese]. São Paulo: Faculdade de Medicina, Universidade de São Paulo; 2019.

Convencionou-se chamar de hipopituitarismo congênito (HC) a deficiência de um ou mais hormônios hipofisários. O HC pode se apresentar na forma de insuficiência isolada do hormônio de crescimento (DIGH) ou combinada com a deficiência de outros hormônios hipofisários - deficiência hipotálamo-hipofisária múltipla (DHHM) e apresenta uma prevalência de um a cada 3.500 a 10.000 nascimentos. O diagnóstico precoce apresenta impacto no tratamento clínico inicial e, posteriormente, no aconselhamento genético. A maioria dos estudos realizados até o momento, que identificou uma etiologia genética para a deficiência hormonal, utilizou a técnica de Sanger. Mais recentemente, o sequenciamento paralelo em larga escala (SPLE) vem sendo utilizado como uma forma de investigação genética mais rápida e a um custo menor, permitindo estender esse processo de sequenciamento a milhares de reações de forma simultânea e automatizada. Os objetivos deste estudo foram: 1) desenvolver um painel customizado de sequenciamento paralelo em larga escala (SPLE) para investigação da etiologia genética da deficiência do hormônio de crescimento congênito e 2) correlacionar os achados moleculares encontrados com o fenótipo. Para este estudo, foram selecionados: 117 pacientes acompanhados no serviço de endocrinologia do Hospital das Clínicas da Universidade de São Paulo (HC-FMUSP), Serviço de Endocrinologia do Hospital do Servidor Público Estadual de São Paulo, Instituto de Assistência Médica ao Servidor Público Estadual (HSPE-IAMSPE), Hospital de Transplantes Euryclides de Jesus Zerbini de São Paulo e Hospital de Niños Santísima Trinidad em Cordoba, Argentina. Métodos: os pacientes foram sequenciados por SPLE, utilizando um painel contendo 26 genes associados ao hipopituitarismo. Como resultados foram encontradas quatro novas variantes patogênicas nos genes OTX2 c.295C $>\mathrm{T}$, GLI2 c.1681G $>\mathrm{T}$, GHRHR c.820_821insC:p.Asp274Alafs*113 e PROP1 c.109+1G>A e variantes previamente classificadas como patogênicas pelos critérios da ACMG / AMP nos genes GHRHR c.57+1G>A e PROP1 c.301_302delAG em cinco pacientes. Os resultados indicaram que um painel projetado sob medida é um método útil para rastrear, simultaneamente, variantes de relevância biológica e clínica para a deficiência congênita de hormônio de crescimento (GH). Um diagnóstico genético foi possível em cinco de 117 (4\%) pacientes desta coorte. Foram identificadas quatro novas variantes patogênicas nos genes GHRHR, GLI2, OTX2 e PROP1, expandindo o espectro de variantes associadas ao hipopituitarismo congênito.

Descritores: Hipopituitarismo, Sequenciamento de Nucleotídeos em Larga Escala, Mutação, Nanismo Hipofisário, Anormalidades Congênitas, Sistema HipotálamoHipofisário 


\section{Abstract}

Nakaguma M. Massive-parallel sequencing by gene panel in the diagnosis of congenital hypopituitarism [thesis]. São Paulo: "Faculdade de Medicina, Universidade de São Paulo"; 2019.

Congenital hypopituitarism can be present as isolated growth hormone deficiency (IGHD) or combined with the impaired production of other pituitary hormones (CPHD) and has an incidence of 1: 3,500 to 10,000 births. Genetic diagnosis has an impact on management and genetic counseling. Most studies to identify the genetic etiology of the hormonal deficiency used Sanger sequencing. Massive-parallel sequencing has been used as a method of faster genetic investigation with reduced costs, allowing extending this sequencing process to thousands of reactions in a simultaneous and automated manner. The objectives of our study are: 1) developing a customized panel for massively-parallel sequencing (MPS) to investigate the genetic etiology of congenital hypopituitarism, and 2) correlate the molecular findings with the phenotype. In this study, 117 subjects were studied from the endocrinology units of Hospital das Clínicas da Universidade de São Paulo (HC-FMUSP), Hospital do Servidor Público Estadual de São Paulo, Instituto de Assistência Médica ao Servidor Público Estadual (HSPE-IAMSPE), Hospital de Transplantes Euryclides de Jesus Zerbini de São Paulo and Hospital de Niños Santísima Trinidad de Cordoba, Argentina. Methods: patients were screened by a target panel containing 26 genes associated to hypopituitarism. As result, four novel pathogenic variants were found in OTX2 c.295C $>$ T, GLI2 c.1681G $>$ T, GHRHR c.820_821insC and PROP1 c.109+1G $>$ A and the previously reported variants in PROP1 c.301_302delAG and GHRHR c.57+1G>A in five patients. In conclusion, our results indicate that a custom designed panel is an efficient method to screen simultaneously variants of biological and clinical relevance for congenital GH deficiency. A genetic diagnosis was possible in 5 out of 117 (4\%) patients of our cohort expanding the spectrum of variants associated with congenital hypopituitarism.

Descriptors: Hypopituitarism, High-Throughput Nucleotide Sequencing, Mutation, Dwarfism, Pituitary, Congenital Abnormalities, Hypothalamo-Hypophyseal System 
1 Introdução 


\section{INTRODUÇÃO}

A deficiência da secreção do hormônio de crescimento (DGH) congênita pode apresentar-se de forma isolada (DIGH) ou combinada com deficiência de outros hormônios hipofisários - deficiência hipotálamo-hipofisária múltipla (DHHM) e apresenta uma prevalência de um a cada 3.500 a 10.000 nascimentos. Convencionouse chamar de hipopituitarismo congênito (HC) a deficiência de um ou mais hormônios hipofisários $^{[1]}$.

O quadro clínico e a forma de apresentação da DGH podem variar de formas clínicas menos evidentes nos casos parciais e/ou de início mais tardio na infância até apresentações graves de DGH. Ao nascimento, o peso e o comprimento costumam estar normais, e o diagnóstico deve ser suspeitado na presença de sintomas como hipoglicemia e icterícia prolongada. Micropênis, criptorquidia e hipoplasia da bolsa escrotal podem ocorrer sobretudo quando associados à deficiência de gonadotrofinas $^{[2]}$.

Com frequência, a baixa estatura e o atraso da velocidade de crescimento são os únicos sintomas presentes no paciente com DGH, normalmente, associados a atraso na idade óssea. Quando não tratada, a estatura pode ficar abaixo de -3 ou -4 desviospadrão em relação à média para idade e sexo ${ }^{[2]}$.

Outros estigmas como obesidade truncal, aumento de espessura de pregas cutâneas, desenvolvimento muscular diminuído, aparência facial infantil com fronte proeminente e nariz em sela, atraso no fechamento das fontanelas, atraso na dentição, cabelos finos e esparsos, voz aguda e infantil também podem estar presentes ${ }^{[3]}$. 
Defeitos de linha média e/ou malformações complexas como agenesia de corpo caloso, displasia septo-óptico, holoprosencefalia ou síndrome da interrupção da haste (PSIS: hipoplasia da adeno-hipófise, afilamento ou transecção da haste hipofisária) e neuro-hipófise ectópica (NHE) estão com frequência associados à deficiência hormonal ${ }^{[4]}$.

Em relação à etiologia do HC, várias evidências apontam para uma possível causa genética: a) sua ocorrência em casos familiares ou em famílias consanguíneas, b) a identificação até o momento de diversos genes como causa da deficiência hormonal e c) sua frequente associação com fenótipos que compartilhem desenvolvimento comum onde causas genéticas já foram estabelecidas, como HPE, DSO, etc ${ }^{[4]}$.

A etiologia genética do HC pode ser classificada, de acordo com o mecanismo molecular que resultou na deficiência de GH, em três grandes grupos:

1. Genes envolvidos na embriogênese hipotálamo-hipofisária

2. Genes envolvidos na diferenciação das células hipofisárias

3. Genes envolvidos diretamente na síntese e secreção de GH.

Nas últimas décadas, diversos estudos avaliaram a frequência e a importância de defeitos envolvidos nestas vias em famílias isoladas e populações de pacientes com DIGH ou DHHM. Estes estudos foram baseados na estratégia da escolha de um gene candidato, que considera a apresentação clínica para identificação de um possível gene relacionado à deficiência hormonal e sequenciamento de Sanger em toda a casuística. Em nosso serviço no Hospital das Clínicas da Universidade de São Paulo, a primeira avaliação com o objetivo de identificar a etiologia genética de HC ocorreu na década de 1990 com o sequenciamento dos genes $G H 1$ e PROP1 ${ }^{[5-8]}$. Até o momento, 
15 genes foram estudados, utilizando a estratégia de gene candidato, por diversos pesquisadores do serviço (PROP1, SOX3, LHX3, LHX4, GLI2, GH1, GHRH, GHRHR, GHRS, HESX1, HES1, OTX2, FGFR1, PROKR2, NEUROD4) [5-36]. Foram encontradas variantes patogênicas nos genes GH1, PROP1, GHRHR, GLI2 e HESX1 e variantes com possível envolvimento nos genes FGFR1 e PROKR2, o que corresponde a cerca de $12 \%$ dos pacientes com etiologia genética identificada. Este dado está em acordo com a literatura na qual a etiologia da deficiência hormonal, na grande maioria dos pacientes (84\%), permanece desconhecida ${ }^{[4,28]}$.

Mais de 30 genes foram identificados, como possível causa genética de DHHM associado a amplo espectro fenotípico ${ }^{[4]}$.

A utilização de sequenciamento paralelo em larga (SPLE) utiliza o mesmo princípio do sequenciamento de Sanger - a identificação em sequência das bases de pequenos fragmentos de DNA - porém permite estender esse processo a milhares de reações em sequenciamento simultâneo de forma automatizada, em menor tempo ${ }^{\text {[37] }}$.

\subsection{ONTOGÊNESE HIPOFISÁRIA}

A glândula hipófise é composta pela adeno-hipófise e pela neuro-hipófise que são estruturas funcionais e morfologicamente distintas, cujos desenvolvimentos estão diretamente relacionados com a presença de sinais gerados pelo diencéfalo em desenvolvimento, assim como a ativação de uma cascata de fatores de transcrição e sinalização que regula a diferenciação celular, proliferação e, posteriormente, a produção de hormônios hipofisários (Figura 1) ${ }^{[1,38]}$. 
A adeno-hipófise é proveniente do ectoderma oral e é responsável pela secreção de seis hormônios GH, LH, FSH, PRL, ACTH e TSH, provenientes de cinco diferentes grupos celulares. A neuro-hipófise é proveniente do neuroectoderma, uma região situada na linha média ventral do diencéfalo - com a formação de outras placas sensoriais (placas olfatórias, óticas e ópticas) - e contém projeções axonais terminais dos neurônios magnocelulares, dos núcleos paraventriculares e supraópticos do hipotálamo, sendo responsável pela produção de oxitocina e hormônio antidiurético $(\mathrm{ADH})^{[39]}$.

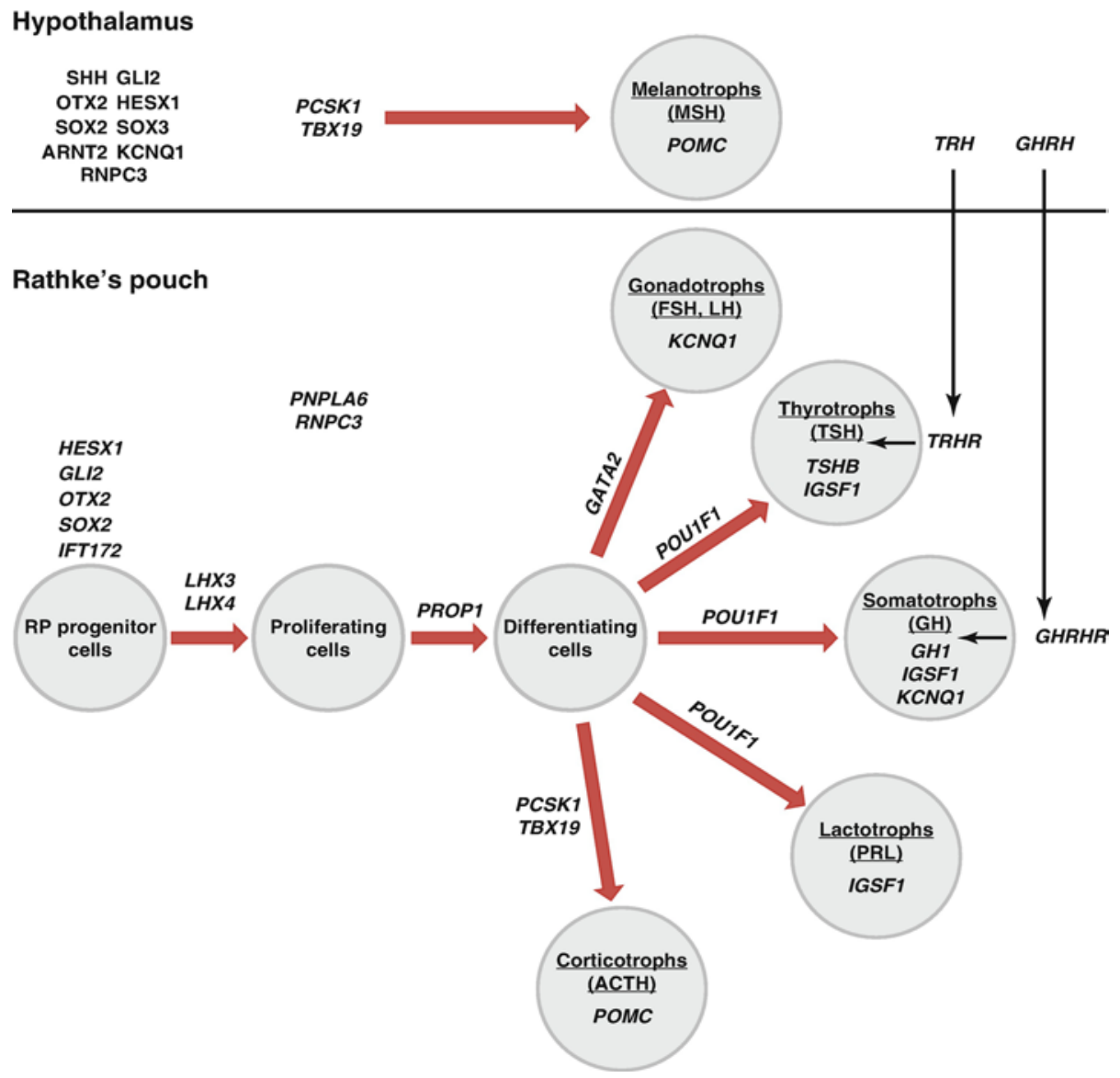

Fonte: Gregory LC e Dattani MT ${ }^{[38]}$

Figura 1 - Desenvolvimento do eixo hipotálamo-hipofisário 


\subsubsection{Defeitos na embriogênese da região hipotálamo-hipofisária}

De forma geral, as frequências de defeitos nestes fatores de transcrição são raras e os quadros clínico e radiológico são bastante heterogêneos ${ }^{[1]}$.

O OTX2 é um fator de transcrição precocemente expresso durante o desenvolvimento embrionário, crítico para o desenvolvimento do diencéfalo ventral, adeno-hipófise, além de órgãos sensoriais como as células olfativas, gânglio coclear, células fotorreceptoras e placa ótica. Mutações nesse gene possuem herança autossômica dominante, frequente penetrância incompleta e ampla variabilidade fenotípica (Tabela 1), com ausência de correlação genótipo-fenótipo demonstrada em diversos casos ${ }^{[40,41]}$. Os pacientes afetados podem apresentar malformação ocular, micrognatia ou agnatia, holoprosencefalia, com a presença ou não de DGH isolada ou combinada.

O HESX1 é um dos marcadores mais precoces do desenvolvimento hipofisário ${ }^{[41,42]}$. Inicialmente, variantes no gene HESX1 foram descritas em associação à DSO, mas podem apresentar-se com um amplo espectro de fenótipos e herança autossômica dominante ou recessiva, como descrito nos dados da Tabela 1. As variabilidades clínica e radiológica podem ocorrer mesmo dentre portadores da mesma mutação, como demonstrado por Carvalho et al, que descreveram pacientes de mesmo genótipo que apresentavam DHHM sem associação com DSO, com a presença de neuro-hipófise tópica (NHT) ou ectópica ${ }^{[11,31] . ~}$

Nos fatores de transcrição da via Sonic Hedgehog (SHH) - como o GLI2 e SHH, variantes são mais estudadas até o momento, como causa de holoprosencefalia ${ }^{[4]}$. Durante o início da embriogênese de vertebrados, o SHH é expresso na notocorda e tubo neural e atua no desenvolvimento do SNC e elementos 
distais dos membros em desenvolvimento ${ }^{[43]}$. França et al identificaram a presença de mutações no GLI2 associadas a DIGH e DHHM e associação variável a defeitos de linha média e polidactilia, com modo de herança autossômica dominante e penetrância incompleta ${ }^{[16,23]}$.

Como outros exemplos de genes envolvidos na embriogênese da região hipotálamo-hipofisária, podem-se citar os genes LHX3, LHX4, SOX3 e PITX2. Suas principais características e modelos de herança das variantes associadas ao hipopituitarismo estão descritos nos dados da Tabela 1.

Tabela 1 - Genes relacionados a defeitos na embriogênese da região hipotálamohipofisária, fenótipo e modelo de herança dos pacientes com hipopituitarismo congênito ${ }^{[4]}$

\begin{tabular}{|c|c|c|}
\hline Gene & Características Sindrômicas & Modelo de Herança \\
\hline GLI2 & DSO, HPE, polidactilia, sindactilia & $\begin{array}{l}\text { Autossômica dominante } \\
\text { e penetrância incompleta }\end{array}$ \\
\hline HESX1 & $\begin{array}{l}\text { DSO, anoftalmia, microftalmia, defeitos do corpo } \\
\text { caloso, outras malformações cerebrais }\end{array}$ & $\begin{array}{c}\text { Autossômica dominante } \\
\text { ou recessiva }\end{array}$ \\
\hline LHX3 & $\begin{array}{l}\text { Dificuldade de rotação e rigidez cervical, deficiência } \\
\text { auditiva }\end{array}$ & Recessiva \\
\hline LHX4 & $\begin{array}{c}\text { Doença respiratórias, malformações genitais e } \\
\text { craniofaciais }\end{array}$ & $\begin{array}{l}\text { Dominante e penetrância } \\
\text { incompleta }\end{array}$ \\
\hline OTX2 & Malformações oculares e craniofaciais & $\begin{array}{l}\text { Dominante e penetrância } \\
\text { incompleta }\end{array}$ \\
\hline PITX2 & Malformações oculares e craniofaciais & Dominante \\
\hline SOX2 & $\begin{array}{c}\text { Malformações em SNC, anoftalmia, déficit intelectual, } \\
\text { deficiência auditiva, atresia esofágica, malformações } \\
\text { genitais }\end{array}$ & $\begin{array}{l}\text { Autossômica dominante } \\
\text { e penetrância incompleta }\end{array}$ \\
\hline SOX3 & $\begin{array}{c}\text { Malformações craniofaciais, retrognatia, déficit } \\
\text { intelectual, deficiência auditiva }\end{array}$ & $\begin{array}{l}\text { Recessiva ligada a X e } \\
\text { penetrância incompleta }\end{array}$ \\
\hline
\end{tabular}




\subsubsection{Defeitos na diferenciação das células hipofisárias}

O PROP-1 é um fator de transcrição da família homeodomíneo paired-like, que é expresso especificamente nas células embrionárias da hipófise, envolvido diretamente na formação e diferenciação dos somatotrofos, lactotrofos, tireotrofos e gonadotrofos. Pode funcionar como ativador ou repressor, conforme a fase em que é expresso, e liga-se como um dímero aos promotores dos genes HESX-1 e POU1F1 (PIT-1) - fatores de transcrição fundamentais para o desenvolvimento hipofisário ${ }^{[44]}$. Mutações identificadas no gene $P R O P 1$ são a causa genética mais frequente de hipopituitarismo com modelo de herança autossômico recessivo e penetrância completa em pacientes com DHHM e NHT [30, 33, 39, 45]. As duas variantes mais prevalentes são as deleções c.301_302delAG e c.150delA, que podem ser explicadas pela ocorrência do fenômeno do efeito fundador ${ }^{[30]}$.

O POU1F1 pertence à família POU dos genes homeobox específicos da hipófise, necessária para a expressão de GH, TSH e PRL. Variantes no POU1F1 foram descritas em pacientes apresentando herança autossômica dominante ou recessiva, NHT com hipoplasia de adeno-hipófise e deficiência de GH, TSH e PRL. Apenas um estudo, que descreveu nove indivíduos afetados em três gerações, correlacionou mutação no gene POU1F1 - isoforma alfa - com apresentação clínica de deficiência de GH isolada ${ }^{[46]}$. 


\subsection{REGULAÇÃO DA SÍNTESE E SECREÇÃO DE GH}

O GH é um hormônio polipeptídico codificado pelo gene GH1, produzido nos somatotrofos - células localizadas na adeno-hipófise ${ }^{[47]}$.

A isoforma principal contém 191 aminoácidos e peso molecular de 22 kDA. Por meio de um mecanismo de splicing alternativo são produzidas diversas isoformas, como 27, 20, 17 e 5 kDa e oligômeros como o "big” e o "big big” GH (>45 kDa) ${ }^{[3,48]}$.

A regulação de sua produção ocorre por meio de dois principais peptídeos hipotalâmicos: o hormônio liberador de GH (GHRH) que estimula a produção de GH e a somatostatina (SST) que inibe sua secreção ${ }^{[3]}$. O GHRH age por meio de um receptor acoplado à proteína Gs que ativa a adenilciclase e eleva os níveis de AMPc intracelular, que estimula a síntese de $\mathrm{GH}^{[47]}$.

Já o GHSR é o receptor do secretagogo de GH, membro da família de receptores acoplados à proteína $\mathrm{G}$ com sete domínios transmembrana, expresso na hipófise e hipotálamo. A isoforma GHSR1a é forma ativa que atua como receptor ligante da grelina - hormônio secretado pelas mucosa gástrica e sistema nervoso central, que tem potente efeito orexigênico e, ao ligar-se ao GHSR, estimula a secreção de $\mathrm{GH}^{[49]}$.

\subsubsection{Defeitos na síntese e secreção de GH}

Em 1981, Phillips et al. examinaram o DNA genômico de crianças suíças com nanismo e descobriram usando a técnica de Southern Blot que o gene GH1 estava ausente. Esta foi uma das primeiras formas de doença monogênica associada a distúrbio de crescimento em que a etiologia genética foi identificada [50]. 
Posteriormente, outras formas de herança relacionadas a mutações no GH1 foram descritas e atualmente são conhecidas quatro formas familiares de DIGH: tipo IA e IB (autossômica recessiva), tipo II (autossômica dominante) e tipo III (recessiva ligada ao $\mathrm{X})^{[50]}$.

Existe uma particularidade de mutações no gene $G H 1$ que pode levar à deficiência hormonal hipofisária combinada que ocorre na forma familiar de DGH tipo II. Nestes casos, há produção aumentada da isoforma de 17,5 kDa que permanece retida no retículo endoplasmático, comprometendo a via de secreção de GH e dos demais hormônios hipofisários. Exceto nessa condição, mutações em genes que participam diretamente da síntese e secreção de GH levam à deficiência de GH isolada com imagem da região hipotálamo-hipofisária normal ${ }^{[51]}$.

Mutações no gene GHRHR devem ser suspeitadas sobretudo nos casos familiares ou consanguíneos com herança recessiva ${ }^{[3]}$. Em 1999, Salvatori R et al. descreveram a maior família já descrita contendo 105 indivíduos afetados em sete gerações, apresentando a mutação GHRHR c.57+1G>A em homozigose - na cidade de Itabaianinha em Sergipe (BR) ${ }^{[52]}$.

Embora o gene GHRH seja um candidato óbvio para investigação como causa de DIGH, estudo multicêntrico realizado por França et al, em uma casuística contendo 151 pacientes com DIGH, não identificou variantes patogênicas causadoras da deficiência hormonal ${ }^{[20]}$. Portanto mutações no $G H R H$ não são uma causa frequente de DIGH ${ }^{[20,48]}$.

No gene GHSR, mutações foram identificadas nas formas de herança recessiva e dominante com penetrância incompleta, associadas a fenótipos variados como baixa 
estatura idiopática, DIGH e atraso constitucional do crescimento e desenvolvimento (ACCD) ${ }^{[19]}$.

Estima-se que 3\% - 30\% dos casos com deficiência isolada de GH tenham etiologia genética com mutações principalmente nos genes GH1 e GHRHR. Outros genes, embora pouco frequentes, também cursam com DIGH e NHT e podem ser investigados ${ }^{[53]}$.

\subsection{O USO DA TÉCNICA DE SPLE NA IDENTIFICAÇÃO DE GENES ASSOCIADOS À DGH CONGÊNITA}

O sequenciamento exômico completo (WES), que consiste na codificação de todas as regiões exônicas, e a utilização de painel que captura apenas regiões de interesse (exônicas ou intrônicas) são as técnicas de SPLE mais comumente utilizadas atualmente.

A taxa de diagnósticos é muito variável e é maior nos casos de doenças com alta probabilidade de condições genéticas subjacentes, doenças monogênicas ou com herança mendeliana bem conhecida ${ }^{[54]}$. O painel, apesar de realizar sequenciamento restrito a regiões-alvo, possibilita a melhoria da cobertura, com o aumento do número de sondas desenhadas para cobertura destas regiões de interesse e também do sequenciamento de regiões intrônicas.

A primeira descoberta de um gene não previamente relacionado à DHHM por meio do WES, ocorreu em 2013 com Webb et al. que descreveram uma variante do tipo frameshift em homozigose no gene ARNT2 identificada em uma família consanguínea com seis indivíduos afetados que apresentavam características 
sindrômicas, além de associação com DHHM ${ }^{[55]}$. Desde esta primeira descoberta, cinco outros genes foram implicados na etiologia de DHHM empregando tal técnica ${ }^{[4]}$.

O presente estudo visa utilizar a técnica de SPLE para determinar o envolvimento de um painel de genes na etiologia do hipopituitarismo congênito. 


\section{Objetivos}




\section{OBJETIVOS}

1. Utilizar um painel customizado de sequenciamento paralelo em larga escala na investigação genética do hipopituitarismo congênito.

2. Correlacionar os achados moleculares com o fenótipo. 
3 Material e Métodos 


\section{MATERIAL E MÉTODOS}

\subsection{CONSIDERAÇÕES ÉTICAS}

O estudo foi conduzido conforme os princípios éticos, seguindo as orientações contidas na declaração de Helsinki e nos termos descritos pela Portaria nº 196/96 do Conselho Nacional de Saúde.

O projeto (FAPESP 13/03236-5) foi submetido à avaliação pela comissão de ética em pesquisa. O consentimento por escrito foi obtido de todos os pacientes e/ou pais/tutores, de acordo com as exigências do Comitê de Ética de cada serviço (Comissão de Ética para Análise de Projetos de Pesquisa no Brasil CAAE e Comité Institucional de Ética de la Investigación en Salud del Niño y del Adulto na Argentina).

\subsection{CASUÍSTICA}

Foram selecionados 117 pacientes, com diagnóstico de DIGH ou DHHM, acompanhados pela Disciplina de Endocrinologia da Faculdade de Medicina da Universidade de São Paulo, na Universidade de Cordoba na Argentina, no Hospital de Transplantes Euryclides de Jesus Zerbini e no Instituto de Assistência Médica ao Servidor Público Estadual (IAMSPE). As características clínicas dos pacientes estão resumidas nos dados da Tabela 2. 


\subsubsection{Diagnóstico da Deficiência de GH}

A presença de deficiência do hormônio de crescimento foi definida pela avaliação combinada do quadro clínico; dosagens de IGF-1 e IGFBP-3, resposta a testes de estímulo de liberação de GH e avaliação por ressonância magnética das estruturas da região hipotálamo-hipofisária. O diagnóstico de DGH pode ser resumido pela Figura 2.

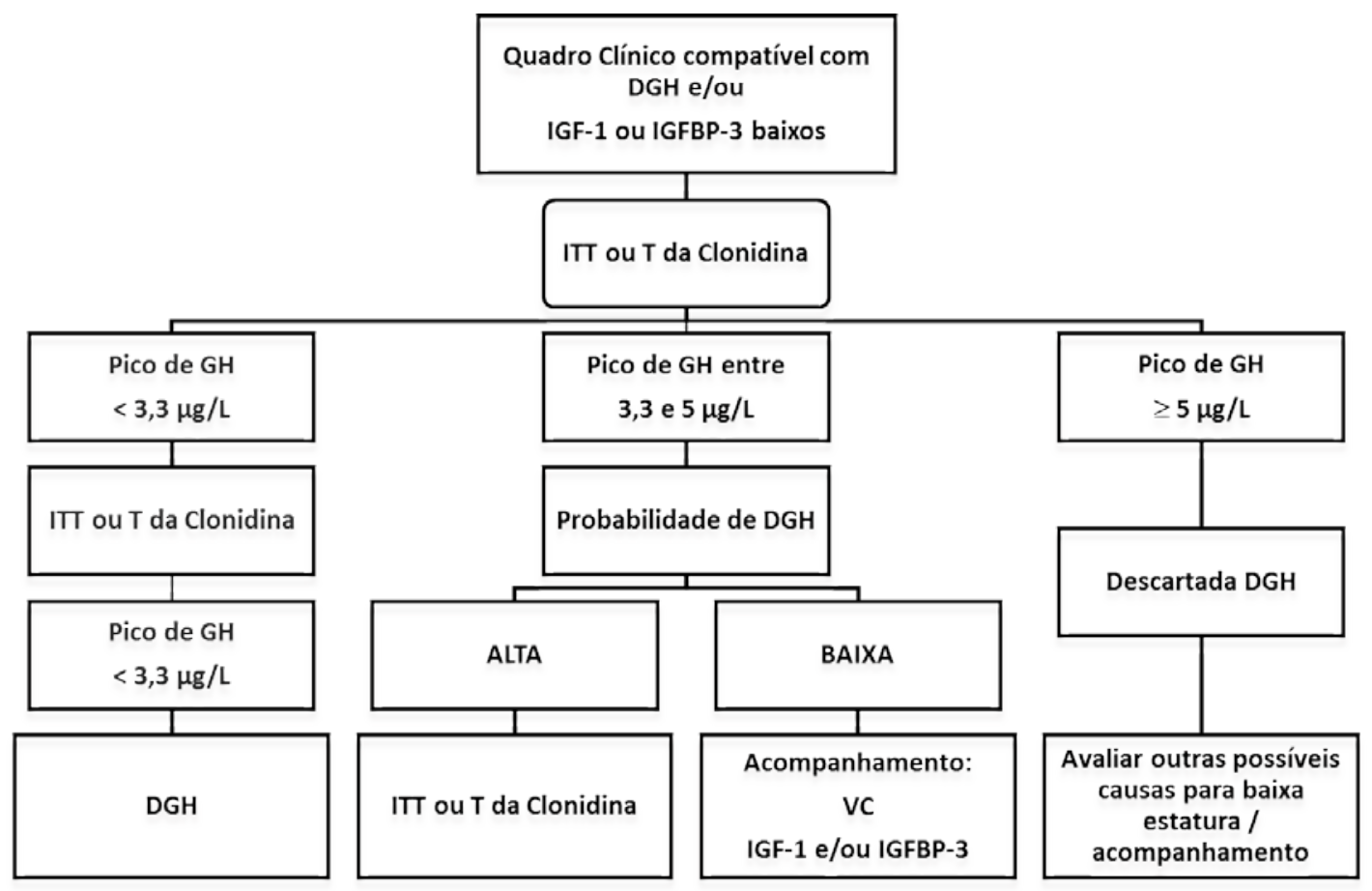

ALTA: presença de neuro-hipófise ectópica e/ou transecção de haste hipofisária, antecedente de tumor, cirurgia ou RT na região hipotálamo hipofisária, causa genética comprovada de deficiência de GH, presença de outras deficiências hipofisários e/ou DI.

Figura 2 - Diagnóstico da deficiência do hormônio de crescimento; DGH: deficiência do hormônio do crescimento,ITT: teste de tolerância a insulina, GH: hormônio de crescimento, IGF-1: insulin-like growth fator, IGFBP3: insulin-like growth fator binding protein, $\mathrm{VC}$ : velocidade de crescimento - adaptado de Berenice BM et al ${ }^{[56]}$

Quadro clínico compatível com DGH pode ser caracterizado ao nascimento pela presença de hipoglicemia (agravada quando à DGH se associa a deficiência de ACTH), icterícia prolongada com hiperbilirrubinemia direta devido à colestase e hepatite de células gigantes. Pode ainda apresentar micropênis, criptorquidia e hipoplasia da bolsa 
escrotal, principalmente quando da associação de deficiência de gonadotrofinas; Quando não tratado, leva principalmente a baixa estatura (Z escore da altura $<-2,0$ ) e associado à presença de estigmas como obesidade truncal, aumento da espessura de pregas cutâneas, desenvolvimento muscular diminuído, aparência facial infantil com fronte proeminente e nariz em sela, atraso no fechamento das fontanelas, atraso na dentição, cabelos finos e esparsos, voz aguda e infantil, e idade óssea atrasada em relação à idade cronológica.

Em relação às dosagens hormonais, o diagnóstico se baseia na presença de IGF-I e IGFBP-3 abaixo de -2 escore-Z para a idade e sexo. Quando é realizado teste de estímulo para a liberação de $\mathrm{GH}$, é considerada falta de resposta ao teste de

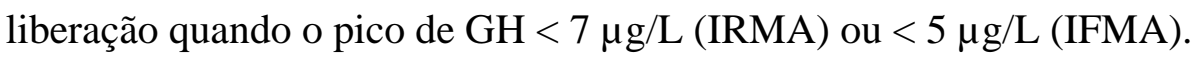

Também foi realizada a avaliação da presença de deficiência dos demais hormônios através de dosagens hormonais basais de LH, FSH, estradiol (sexo feminino) testosterona total (sexo masculino), sulfato de deidroepiandrosterona (DHEAS), TSH, T4 livre, T4 total e prolactina. Alguns pacientes foram submetidos a teste de estímulo para avaliação de deficiência de cortisol utilizanto o teste de insulina ou teste com ACTH sintético (250 mcg/IV). A resposta de cortisol, após hipoglicemia ou ACTH sintético, foi considerada normal quando ocorreu incremento $>8 \mu \mathrm{g} / \mathrm{dL}$ e um pico de cortisol > 18 g/dL e como deficiência parcial de ACTH quando ocorreu um incremento no valor de cortisol sem atingir o pico de $18 \mu \mathrm{g} / \mathrm{dL}$. Deficiência de TSH foi determinada por baixas concentrações de T4 livre e/ou T4 total com concentração de TSH baixa ou normal. Hipogonadismo hipogonadotrótico foi definido pela ausência de desenvolvimento de caracteres sexuais secundários, após 13 anos nas meninas e 14 anos nos meninos, e concentrações de LH e FSH indetectáveis ou 
normais. Deficiência de prolactina foi determinada pelo valor de máximo de prolactina $<20 \mu \mathrm{g} / \mathrm{L}$ (RIA), após estímulo com TRH. Deficiência de ADH foi definida pela densidade urinária <1010 e volume urinário > $50 \mathrm{ml} / \mathrm{kg}$ em 24h e/ou naqueles pacientes com prova de privação hídrica compatível com diabetes insipidus neurogênico.

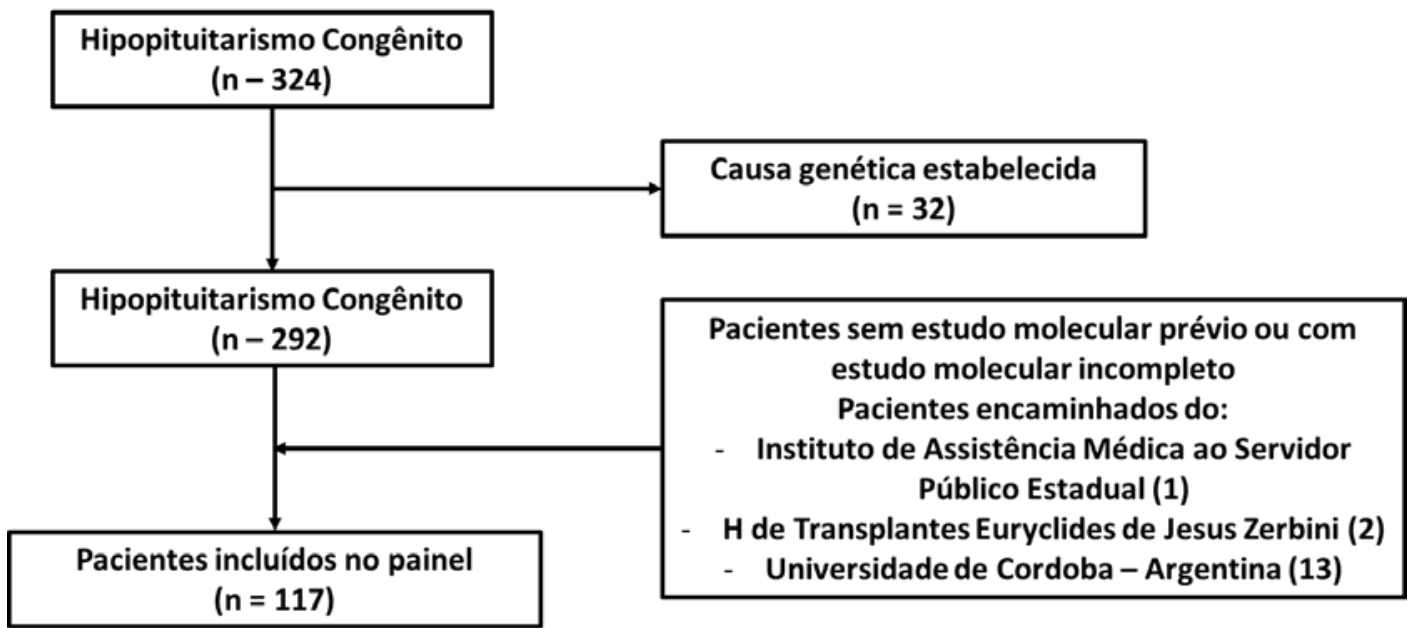

Figura 3 - Pacientes selecionados para estudo 
Tabela 2 - Caracterização dos pacientes selecionados para estudo

\section{Características}

$\mathbf{N}$

Sexo (F:M)

Idade inicial

Mediana (intervalo)

Consanguinidade

Baixa estatura referida na família

$\mathrm{Z}$ da altura ao diagnóstico

Mediana (intervalo)

Deficiência hormonal

DIGH

DHHM

TSH

ACTH

LH/ FSH

ADH

\section{Pico de GH}

Mediana (intervalo)

\section{Localização da neuro-hipófise}

Tópica

Ectópica

Não visualizada

\section{Adeno-hipófise}

Ausente

Hipoplásica

Normal

Não descrita
117

53:64

9,5

(6 dias a 43,8)

8

29

$-3,8$

$(-0,3$ a $-7,8)$

90

70

59

56

7

0,9

(indetectável a 5,1)

\section{Outros achados de RM}

DSO

Meningocele esfenoidal

Microadenoma

Malformação de Chiari

Outros

DIGH: deficiência isolada do hormônio de crescimento; DHHM: deficiência hipotálamo-hipofisária múltipla; TSH: hormônio tireoestimulante; ACTH: hormônio adenocorticotrófico; LH: hormônio luteinizante; FSH: hormônio folículo-estimulante; ADH: hormônio antidiurético; DSO: displasia septo-óptica;

* As imagens de ressonância magnética estavam indisponíveis em dois pacientes 


\subsection{SEQUENCIAMENTO}

\subsubsection{Extração do DNA genômico}

As amostras de DNA dos pacientes selecionados e familiares foram obtidas a partir de leucócitos de sangue periférico ou de células extraídas por esfregaço da mucosa oral. O DNA foi extraído de acordo com o procedimento padronizado no Laboratório de Hormônios e Genética Molecular da Unidade de Endocrinologia do Desenvolvimento, Faculdade de Medicina da Universidade de São Paulo.

A concentração do DNA extraído foi obtida por leitura em espectrofotômetro no comprimento de onda de $260 \mathrm{~nm}$ (1 unidade DO $260=50 \mu \mathrm{g} / \mathrm{mL}$ ). A relação ideal entre as leituras entre 260 e 280 nm para caracterização da pureza do material foi superior a 1,75 . As amostras foram mantidas congeladas a $-20^{\circ} \mathrm{C}$ até seu uso.

\subsubsection{Desenho de sondas de captura do painel}

O painel customizado para o sequenciamento de nova geração de genes relacionados ao DIGH ou DHHM foi elaborado a partir da ferramenta Agilent SureDesign 2.0 (Agilent Technologies, Santa Clara, CA, EUA). Esta ferramenta desenha sondas específicas para seleção e captura das regiões genômicas de interesse, com base na metodologia SureSelectXT (Agilent Technologies, Santa Clara, CA, EUA).

O desenho do estudo foi realizado em janeiro de 2015 e optou-se pela inclusão de 26 genes conhecidos e candidatos até então relacionados ao hipopituitarismo GH1, GHRH, GHRHR, GHSR, PROP1, POU1F1, GLI2, HESX1, LHX3, LHX4, OTX2, 
PITX2, ARNT2, DMXL2, FGF8, FGFR1, GPR161, HHIP, IGSF1, KAL1, PROKR2, RNPC3, SHH, SOX2, SOX3 e TGIF1.

Para o preparo das bibliotecas, foi utilizado um kit de sondas customizado para regiões exônicas. Para o gene GH1, optou-se pela inclusão da região promotora.

\subsubsection{Genotipagem por sequenciamento de nova geração}

As bibliotecas do painel foram elaboradas de acordo com o protocolo SureSelectXT Target Enrichment System for Illumina Paired-End Sequencing Library (Agilent Technologies, Santa Clara, CA, EUA).

O sequenciamento do painel foi realizado utilizando a plataforma Illumina (Illumina, Inc, San Diego, CA, EUA), produzindo sequências paired-end (quando as duas extremidades da molécula do DNA são lidas) de 36 a 100 pares de bases, permitindo leituras de fragmentos de até 200 pares de base.

O enriquecimento e o sequenciamento envolveram três etapas fundamentais descritas a seguir e resumidas nos dados da Figura 4.

ETAPA I. Confecção de bibliotecas de fragmentos de DNA: o DNA genômico foi fragmentado de forma mecânica por ultrassonicação centrada, utilizando a plataforma E220 Focused Ultrasonicator (Covaries, Wonurm, MA, EUA). Foram adicionados adaptadores e índex que permitiram a identificação de cada uma das amostras. As regiões de interesse foram então capturadas e enriquecidas, utilizando sondas complementares de RNA.

ETAPA II. Amplificação clonal: nesta etapa, as bibliotecas são depositadas em uma lâmina especial, denominada flowcell, em cuja superfície encontram-se fixados oligonucleotídeos complementares às moléculas adaptadoras presentes nas 
bibliotecas. Cada molécula é amplificada várias vezes (clusterização) por meio de uma reação conhecida como PCR em ponte. Ao final desta etapa, são gerados clones da biblioteca original ligados covalentemente à superfície da flowcell.

ETAPA III. Sequenciamento: após a amplificação clonal, as moléculas antissenses são removidas enzimaticamente e o processo de sequenciamento é iniciado com o acoplamento de um oligonucleotídeo iniciador especial. Em seguida, nucleotídeos modificados com terminadores reversíveis marcados com fluoróforos são adicionados ao meio. A cada ciclo de incorporação, são geradas imagens de toda a superfície da flowcell por um scanner de fluorescência em cada um dos comprimentos de onda específicos para cada fluoróforo. Os clones presentes na superfície da flowcell são então identificados e mapeados. A sobreposição das imagens produzidas a cada ciclo de incorporação propicia a identificação da sequência de bases nucleotídicas de cada grupo de moléculas. 
2000000000000

$200000000000 \mathrm{C}$

\section{$\$ 00000000$} 2000020000 2000020000 $+$

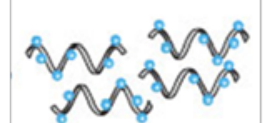

ETAPA I: Fragmentação mecânica (Covaries) e ligação de adaptadores

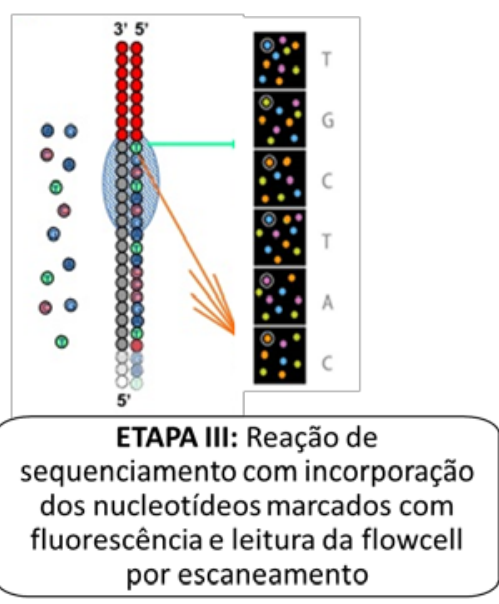

20000200050000

$200600000 \mathrm{c} 3000 \mathrm{~s}$ $00000 \quad 2000 c$

$+$

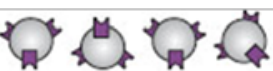

ETAPA I: Ligação das bead

ETAPA I: Hibridação das sondas biotiniladas às regiões de interesse (éxons ou região promotora)

magnéticas com estreptavidina à sondas biotiniladas)

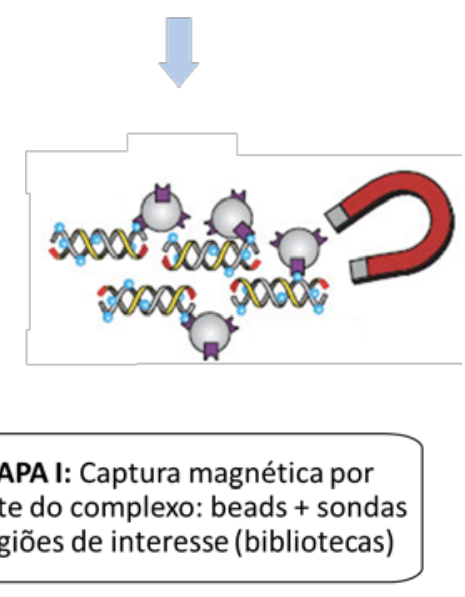

Fonte: adaptado de https://www.illumina.com/

Figura 4 - Sequenciamento paralelo em larga escala 


\subsection{ANÁLISE DE BIOINFORMÁTICA}

O grande volume de dados gerados pelas novas plataformas de sequenciamento requer o emprego de ferramentas computacionais específicas para o tratamento/processamento de toda informação genômica obtida. O fluxo de análise é constituído por etapas que incluem: 1) Análise/controle de qualidade do dado bruto; 2) Alinhamento ao genoma referência humano; 3) Chamada das variantes (genotipagem) e 4) Anotação. O processamento dos dados foi realizado em colaboração com o pesquisador Dr. Antonio Marcondes Lerário da Universidade de Michigan.

1) Análise e controle de qualidade do dado bruto: checagem da estrutura e integridade dos arquivos e cálculo de estatísticas básicas, como número de sequências produzidas.

Programas utilizados: md5sum (https://linux.die.net/man/1/md5sum), FASTQ Groomer e FASTQC ${ }^{[57]}$.

2) Alinhamento ao genoma referência humano: alinhamento dos fragmentos sequenciados (reads) (contidos em arquivos chamados FastQ) a uma sequência referência do genoma humano (hg19 UCSC ou b37 GRC/NCBI). Como o alinhamento é feito sequência a sequência individualmente, torna-se necessário recalibrar o alinhamento realizado na fase anterior, visto que, em algumas situações, diferentes sequências oriundas da mesma região cromossômica apresentam resultados ligeiramente diferentes de mapeamento (por exemplo, quando existem pequenas inserções, deleções ou repetições no genoma-alvo). A 
recalibragem pode ser considerada um realinhamento, mas agora de forma contextualizada.

Programa utilizado: BWA (Burrows-Wheeler Aligner) ${ }^{[58]}$.

3) Chamada das variantes (genotipagem): a partir do melhor alinhamento possível, é realizada a genotipagem da amostra, que consiste em determinar, com bases estatísticas, todos os alelos existentes. Após isso, uma recalibragem da genotipagem é realizada com o objetivo de remover variantes falso-positivas.

Programas utilizados: FreeBayes (Bayesian genetic variant detector) (variantes pontuais e pequenos indels); CONTRA ${ }^{[59]}$ (copy number variations - CNVs).

4) Anotação: esta etapa consiste em anotar as variantes identificadas e simular, computacionalmente, o impacto funcional de cada uma delas. Programas utilizados: SnpEff (http://snpeff.sourceforge.net/) e ANNOVAR (http://www.openbioinformatics.org/annovar)

\subsection{SELEÇÃO DAS VARIANTES CANDIDATAS}

Foram selecionadas variantes alélicas localizadas em regiões exônicas e sítios de splicing com uma frequência populacional (Minor Allele Frequency - MAF) $<1 \%$ em bases de dados públicos: (global) gnomAD (http://gnomad.broadinstitute.org/) e (local) $\mathrm{ABraOM}{ }^{[60]}$ (http://abraom.ib.usp.br/). Em seguida, foram priorizadas variantes com potencial de patogenicidade, variantes de perda de função (LoF). As variantes foram classificadas conforme os critérios da ACMG / AMP utilizando o 
programa de classificação de variantes Varsome (https://varsome.com/) que utiliza os programas de predição de patogenicidade e/ou análise de conservação: DANN ${ }^{[61]}$, DEOGEN2 ${ }^{[62]}$, EIGEN ${ }^{[63]}$, FATHMM ${ }^{[64]}$, GERP ${ }^{[65]}$, LRT ${ }^{[66]}$, MutationAssessor ${ }^{[67]}$, Mutation Taster ${ }^{[68]}$, MutPred2 ${ }^{[69]}$, PROVEAN ${ }^{[70]}$, REVEL ${ }^{[71]}$, SIFT ${ }^{[72]}$, MetaSVM MetaLR [73].

Para avaliação de patogenicidade em região de splicing foram utilizados os preditores dbscSNV ${ }^{[74]}$, Human Splicing Finder Version 2.4.1 ${ }^{[75]}$ e NetGene2 ${ }^{[76] .}$

As variantes candidatas foram confirmadas utilizando-se o Integrative Genomics Viewer (IGV) para reduzir chamadas falso-positivas.

Todas as variantes consideradas potencialmente patogênicas foram confirmadas nos pacientes e em seus familiares, quando disponíveis, por sequenciamento de Sanger.

As seguintes ferramentas foram utilizadas para auxiliar no processo de priorização das variantes alélicas e as possíveis correlações genótipo-fenótipo:

- OMIM (https://www.omim.org/)

- Pubmed (https://www.ncbi.nlm.nih.gov/pubmed/)

- GeneCards (http://www.genecards.org/)

- Human Protein Atlas (http://www.proteinatlas.org/)

- HGMD (http://www.hgmd.cf.ac.uk/) 
As variantes potencialmente candidatas foram classificadas utilizando-se os critérios de avaliação publicados pela The American College of Medical Genetics and Genomics e The Association for Molecular Pathology (ACMG / AMP) como:

1. Patogênica 2. Provavelmente patogênica 3. Variante de significado incerto (VUS) 4. Provavelmente benigna e 5. Benigna (Anexo 2) 
4 Resultados 


\section{RESULTADOS}

\subsection{RESULTADOS MOLECULARES}

A profundidade da cobertura média das regiões codificadoras em nosso painel foi 426 (mediana 295) e, pelo menos, 99,6\% das bases sequenciadas foram cobertas mais de 20 vezes (Tabela 3).

Tabela 3 - Métricas do sequenciamento

\begin{tabular}{lc}
\hline Cobertura $(x \pm D P)$ & $426 \pm 417$ \\
\hline \% com cobertura $>\mathbf{1 0 x}$ & 99,81 \\
\% com cobertura $>\mathbf{2 0 x}$ & 99,62 \\
\hline
\end{tabular}

Nos 117 pacientes com diagnóstico de hipopituitarismo congênito avaliados pelo painel de genes foram encontradas: seis variantes patogênicas (quatro novas) em cinco genes em cinco pacientes (Tabela 4 e Tabela 5), 16 variantes de significado incerto (Anexo 1) e duas variantes (uma nova) em dois genes em três pacientes que apresentam caraterísticas que sugerem ser possivelmente patogênicas (Tabela 6).

Foram identificados variantes patogênicas responsáveis pelo fenótipo de hipopituitarismo em cinco dos 117 pacientes (Tabela 4 e Tabela 5). Estas variantes estavam em genes diretamente envolvidos no desenvolvimento hipofisário (GLI2, 
OTX2), na diferenciação celular hipofisária (PROP1) ou na secreção de GH (GHRHR). Todas as variantes estavam ausentes ou eram extremamente raras em bancos de dados locais e públicos (Tabela 4).

Duas variantes patogênicas em heterozigose do tipo nonsense foram identificadas nos genes GLI2 c.1681G>T e OTX2 c.295C>T, pacientes 1 e 2 (Tabela 4).

Duas variantes patogênicas em heterozigose composta foram identificadas no gene PROP1 (c.301_302del; c.109+1G>A) no paciente 3. A variante c.109+1G>A foi identificada pela primeira vez neste painel e recentemente publicada com uma coorte de pacientes brasileiros portadores de mutações no gene PROP1 [33].

No gene GHRHR foram identificadas variantes em homozigose em duas pacientes: na paciente 4, foi identificada uma variante em região consenso de splicing c.57+1G>A e na paciente 5, uma inserção levando a um frameshift c.820_821insC. 
Tabela 4 - Variantes patogênicas identificadas pelo painel de genes em uma coorte de 117 pacientes com hipopituitarismo congênito

\begin{tabular}{|c|c|c|c|c|c|c|c|c|c|}
\hline Paciente & Gene & Variante & $\begin{array}{l}\text { Sequência } \\
\text { Referência }\end{array}$ & Tipo & GnomAD & ABraOM & Herança & $\begin{array}{l}\text { Evidência de } \\
\text { patogenicidade para } \\
\text { classificação da } \\
\text { ACMG/AMP }\end{array}$ & $\begin{array}{l}\text { Classificação } \\
\text { ACMG/AMP }\end{array}$ \\
\hline 1 & GLI2 & c.1681G>T:p.Glu561* & NM_005270.4 & Nonsense & 0 & 0 & Heterozigose & PVS1, PM2, PP3 & Patogênica \\
\hline 2 & OTX2 & c.295C>T:p.Gln99* & NM_172337.2 & Nonsense & 0 & 0 & Heterozigose & PVS1, PM2, PP3 & Patogênica \\
\hline 3 & PROP1 & c. $109+1 G>A$ & $\begin{array}{l}\text { NM_006261.4 } \\
\text { rs193922688 }\end{array}$ & $\begin{array}{l}\text { Sítio de } \\
\text { splicing }\end{array}$ & 0 & 0 & $\begin{array}{l}\text { Heterozigose } \\
\text { composta }\end{array}$ & PVS1, PM2, PP3 & Patogênica \\
\hline 4 & GHRHR & c. $57+1 \mathrm{G}>\mathrm{A}$ & $\begin{array}{c}\text { NM_000823.3 } \\
\text { rs2302022 }\end{array}$ & $\begin{array}{l}\text { Sítio de } \\
\text { splicing }\end{array}$ & 0,00001957 & 0 & Homozigose & PVS1, PM2, PP3 & Patogênica \\
\hline
\end{tabular}




\subsection{FENÓTIPO DOS PACIENTES COM VARIANTES PATOGÊNICAS}

Todos os pacientes apresentavam deficiência grave de GH (mediana de altura na primeira consulta de $-5,0$, variando de $-7,8$ a $-4,4$ ) (Tabela 5). Em relação às características de base, como peso e comprimento ao nascer, idade na primeira visita e pico de GH, os pacientes com variantes patogênicas não foram diferentes daqueles com resultados moleculares negativos.

\subsubsection{Paciente com a variante $G L I 2$ c.1681G > T}

Paciente 1, sexo masculino, sem história de consanguinidade na família, apresentou relato de complicações durante o parto, hemorragia com necessidade de transfusão em razão da presença de placenta prévia e provável pré-eclampsia. Apresentou desenvolvimento neuropsicomotor normal. Aos 6 anos, procurou atendimento por baixa estatura com altura de $92 \mathrm{~cm}$ (Z da altura -4,4) e idade óssea (IO) de 1,5 anos. Foi realizado teste de estímulo com clonidina, apresentando pico de GH de 2,9 $\mathrm{ng} / \mathrm{ml}$ e teste do glucagon com pico de GH de 6,0 $\mathrm{ng} / \mathrm{ml}$ (dosado por radioimunoensaio com anticorpos policlonais). $\mathrm{O}$ paciente fez uso de rGH (somatropina recombinante humana) dos 6 aos 20,5 anos e evoluiu com puberdade espontânea aos 13 anos, alcançando altura adulta de 167,5 cm (Z da altura -1,0). A ressonância magnética (RM) de sela demonstrou presença de NHE com transecção de haste. O paciente foi submetido a reteste com teste de tolerância a insulina (ITT) para deficiência de GH na fase adulta - sem o uso de rGH por 1 ano - com pico de GH 4,3 ng/ml e IGF-1 208 ng/dl (VR para a idade cronológica: 116 a 341 ng/dl). A resposta ao cortisol foi normal com pico de 20,6 $\mu \mathrm{g} / \mathrm{dl}$ e a prolactina basal de $42 \mathrm{ng} / \mathrm{ml}$. 
Neste paciente, foi identificada uma variante no gene GLI2 c.1681G>T (p.Glu561*) que ocasiona um códon de parada prematuro com perda de 1.026 dos 1.587 aminoácidos. A segregação confirmou a presença da mesma variante em sua mãe com baixa estatura (DP da altura de -4,0) e NHE. Seu tio e primo maternos apresentavam relato de polidactilia, mas o estudo genético não pôde ser realizado.

\subsubsection{Paciente com a variante $O T X 2$ c.295C $>$ T}

O paciente 2, sexo masculino, sem história de consanguinidade, nascido de parto normal, a termo, $3.450 \mathrm{~g}, 47 \mathrm{~cm}$ de comprimento, sem complicações ao nascimento. Apresentou atraso no desenvolvimento psicomotor, engatinhou aos 2 anos e andou aos 3. Este paciente iniciou acompanhamento recentemente em nosso serviço e em sua primeira consulta aos 7 anos, apresentava altura de $87 \mathrm{~cm}$ (Z da altura -6,1). IGF-1 não detectável e atraso de idade óssea (IO de 2 anos). Foram realizados testes de estímulo com clonidina com pico de $\mathrm{GH}<0,1 \mathrm{ng} / \mathrm{mL}$ e RM de sela, demonstrando hipoplasia de adeno-hipófise, NHE, e displasia septo-óptica com sinais de microftalmia à direita com redução das dimensões do nervo óptico direito. Este paciente iniciou acompanhamento recente em nosso serviço e ainda está em tratamento com rGH.

Foi identificada uma variante nonsense, em heterozigose no gene OTX2 c.295C>T (p.Gln99*) que leva a um códon de parada prematuro com perda de 190 aminoácidos. Esta variante foi confirmada no paciente, em sua mãe de fenótipo normal, uma meia irmã com diagnóstico de microftalmia, um meio irmão com malformação em ouvido interno e externo e estrabismo e uma tia materna com 
diagnóstico de Tetralogia de Fallot e atresia tricúspide, sem anomalias craniofaciais e todos com altura normal. 


\subsubsection{Paciente com variantes PROP1 [c.301_302del];[ c.109+1G>A]}

O paciente 3, sexo masculino, sem história de consanguinidade, nasceu de parto normal, sem outros dados do nascimento, e apresentou desenvolvimento neuropsicomotor normal. Ele iniciou acompanhamento em nosso serviço já em idade adulta. Relata uso de rGH dos 18 aos 22 anos de forma irregular, chegando a uma altura final de 144 cm (Z da altura -4,6). O paciente apresentou deficiência de LH/FSH, iniciando reposição com ésteres de testosterona a partir dos 22 anos. Sua RM de hipófise demonstrava sela parcialmente vazia, adeno-hipófise hipoplásica, NHT e haste íntegra.

Foram identificadas duas variantes em heterozigose composta no gene PROP1

- uma variante já previamente descrita na literatura como c.301_302del (p.Leu102Cysfs*8) e uma que troca uma guanina (G) por uma adenosina (A) em região consenso (+1) de splicing, (c.109+1G>A) localizada entre o primeiro íntron e segundo éxon, também predita como patogênica pelos programas Human Splicing Finder Version 2.4.1 NetGene2 e visualizada no IGV (Figura 5).

Pela indisponibilidade do DNA dos pais, a segregação foi realizada apenas em seu irmão não afetado, sendo encontrada apenas deleção c.301_302del, confirmando que as variantes estavam presentes em diferentes alelos (Figura 6). 


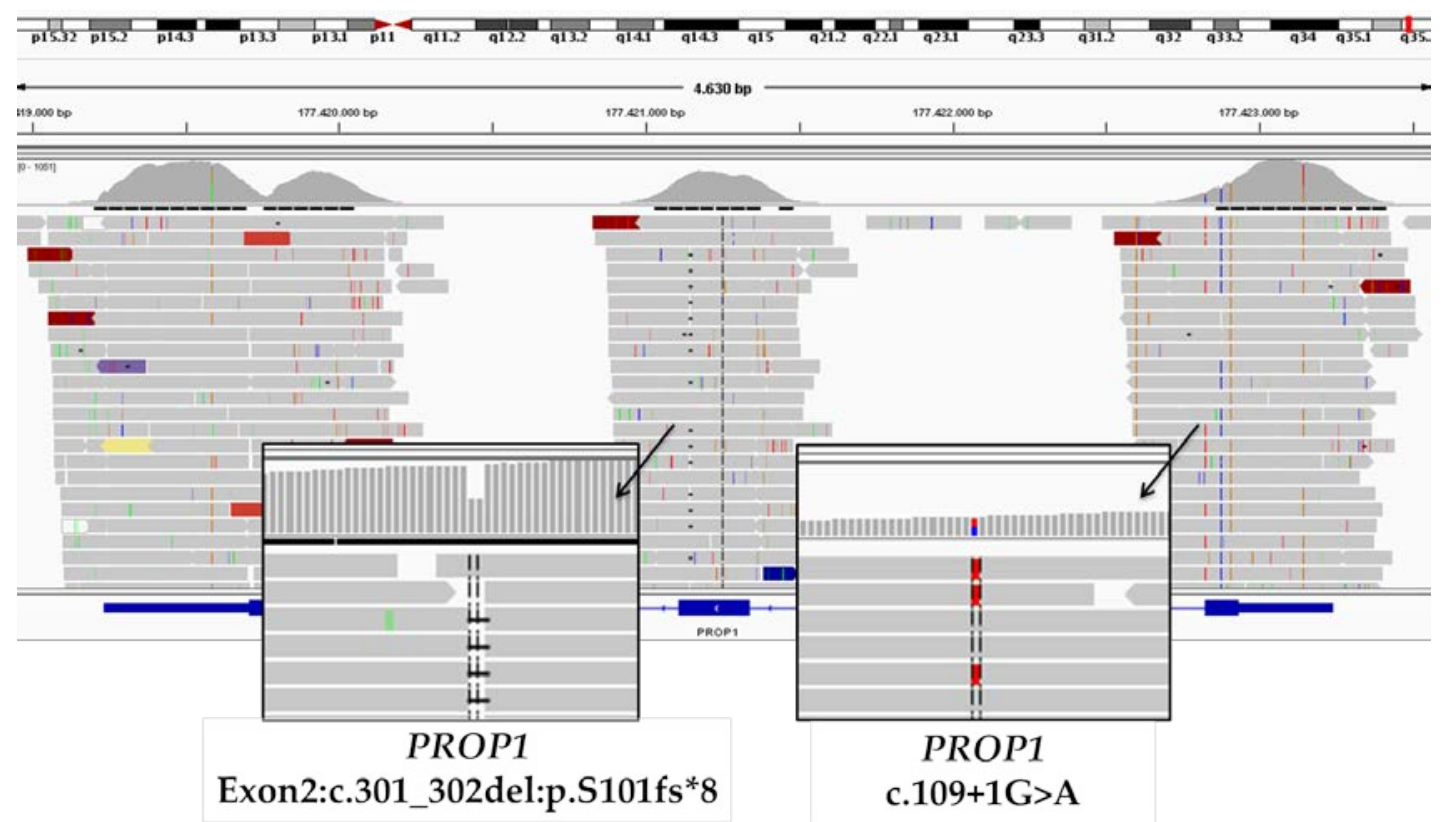

Figura 5 - Visualização das variantes encontradas no gene PROP1 no programa IGV (Integrative Genomics Viewer). Cada barra cinza corresponde a uma "read" (uma vez em que aquela região foi sequenciada). A deleção c.301_302del:p.S101fs*8 é visualizada pela descontinuidade do "read” e a variante em sítio de splicing c.109+1G>A no gene PROP1 identificada no painel pela presença de duas cores, o que significa que aquela região foi lida como adenina (A) (cor vermelha) no lugar de guanina (G) (cor azul)
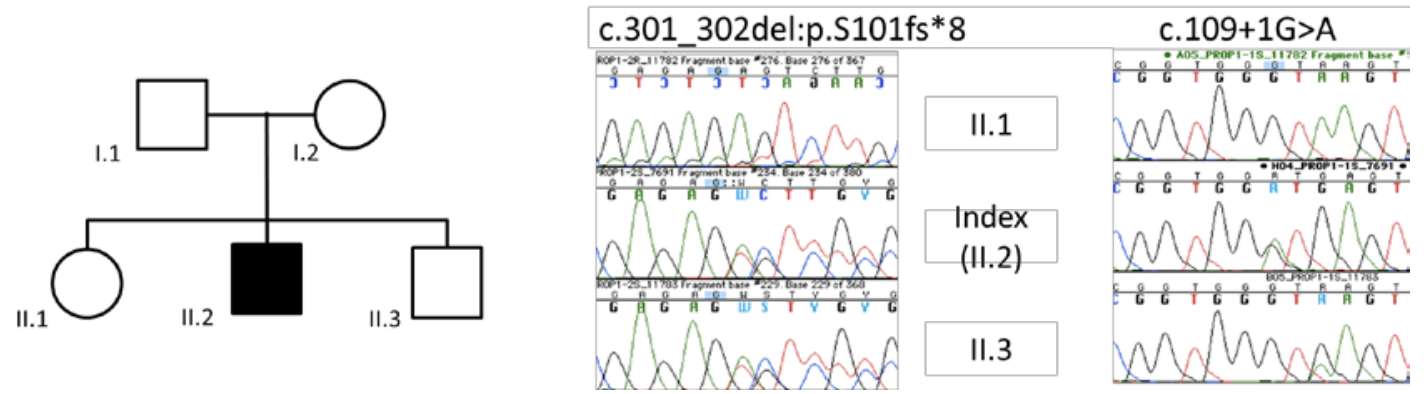

Figura 6 - Eletroferograma do sequenciamento por Sanger das variantes no gene PROP1 que confirmou que o irmão não afetado (II.3) apresenta apenas uma variante. 


\subsubsection{Pacientes com variantes GHRHR [c.57+1G>A];[ c.57+1G>A] e GHRHR [c.820_821insC];[ c.820_821insC]}

A paciente 4, sexo feminino, nascida a termo por parto cesárea, pais consanguíneos, adequada para a idade gestacional, com 2.506 g e 47cm. Na primeira avaliação aos 9,6 anos, ela apresentava altura de 101,5cm (Z da altura -5,2) e IO de 5,5 anos. Foi submetida ao teste de clonidina confirmando deficiência de GH (pico de GH 0,3 ng /mL) e RM de hipófise normal. A paciente foi submetida a reteste aos 14 anos de idade, demonstrando um nível basal de IGF-1 de 122 ng/ml (<-2SD) e ITT com pico de GH de 0,2 ng/ml confirmando sua deficiência de GH. A paciente recebeu tratamento com rGH dos 15,1 aos 16,7 anos, apresentando altura final de 144,2 cm (Z da altura -2,9).

O painel identificou a variante em homozigose no gene GHRHR c.57+1G>A (rs2302022) previamente publicada por Salvatori et al., que leva à perda do sítio canônico de splicing e formação de uma proteína truncada ${ }^{[52]}$.

A paciente 5 iniciou acompanhamento já adulta com diagnóstico de DIGH sem tratamento prévio e não apresenta dados do nascimento disponíveis. RM demonstrando hipoplasia de adeno-hipófise e neuro-hipófise não visualizada. Foi identificada a variante em homozigose c.820_821insC (p.Asp274Alafs*113) inserção que leva a um frameshift seguido de um códon de parada, confirmada em homozigose no caso índex e em seu irmão com fenótipo de baixa estatura. 
Tabela 5- Características clínicas dos pacientes com variantes patogênicas

\begin{tabular}{|c|c|c|c|c|c|c|c|c|c|}
\hline Pacientes & Gene & Sexo & Parto & $\begin{array}{l}\text { História } \\
\text { familiar }\end{array}$ & Idade & $\begin{array}{l}\text { DP da } \\
\text { altura }\end{array}$ & $\begin{array}{c}\text { Deficiência } \\
\text { hormonal }\end{array}$ & Imagem & Outros fenótipos \\
\hline 1 & GLI2 & M & $\begin{array}{c}\text { Cesárea, } \\
\text { hemorragia } \\
\text { durante o parto }\end{array}$ & $\begin{array}{c}\text { Baixa } \\
\text { estatura }\end{array}$ & 6,0 & -4.4 & DIGH & Neuro-hipófise ectópica & Ausente \\
\hline 2 & OTX2 & M & Normal & Não & 7,0 & -6.1 & DIGH & $\begin{array}{l}\text { Neuro-hipófise ectópica } \\
\text { Displasia septo-óptica }\end{array}$ & $\begin{array}{c}\text { Microftalmia, } \\
\text { nistagmo, atraso do } \\
\text { DNPM }\end{array}$ \\
\hline 3 & PROP1 & M & Normal & Não & ND & -7.8 & $\begin{array}{l}\text { DGH, TSH, } \\
\text { ACTHp }\end{array}$ & $\begin{array}{l}\text { Aplasia de adeno- } \\
\text { hipófise, neuro-hipófise } \\
\text { tópica }\end{array}$ & Ausente \\
\hline 4 & GHRHR & $\mathrm{F}$ & Cesárea & Não & 9,6 & -5.2 & DIGH & Normal & Surdez \\
\hline
\end{tabular}

ND: não disponível, NV: não visualizado; DIGH: deficiência isolada do hormônio de crescimento; DGH: deficiência do hormônio de crescimento; DNPM: desenvolvimento neuropsicomotor 


\subsection{VUS DE INTERESSE}

Dentre as variantes classificadas como VUS, foram selecionadas duas de significado incerto nos genes TGIF1 c.82T> C e GHSR c.545T>C. Esta última foi identificada em dois pacientes. Estas variantes foram selecionadas como de interesse por apresentarem associação anterior à deficiência de GH e estudos funcionais prévios realizados no mesmo códon, demonstrando perda de função na proteína. No entanto, não foi possível classificá-las como patogênicas pelos critérios do ACMG / AMP.

\subsubsection{Pacientes com a variante GHSR c.545T $>C$}

O paciente 6, sexo masculino, sem história de consanguinidade, nasceu de parto vaginal normal, a termo, 3.510 g, 50 cm de comprimento, sem complicações ao nascimento e apresentou desenvolvimento neuropsicomotor normal. O paciente iniciou acompanhamento aos 13,2 anos com altura de 129,5 cm (Z da altura -3,4), IO de 8 anos. Aos 15,3 anos, exames laboratoriais demonstravam IGF-1 de 54 ng/mL (<-2 DP). Foram realizados dois testes de estímulo com clonidina com pico de GH de 2,2 ng/mL e teste de tolerância a insulina (ITT) com pico de GH de 0,72 ng/mL, sem outra deficiência hormonal associada. A RM de hipófise apresentava hipoplasia de adeno-hipófise, haste hipofisária íntegra e a presença de hipersinal em T1 na transição da haste hipofisária e adeno-hipófise, podendo corresponder a cisto hiperproteico ou a NHE. O paciente apresentou puberdade espontânea aos 15,2 anos, ainda com altura de 137,0 cm (Z da altura -3,9), recebeu tratamento com rGH dos 15,2 aos 18,9 anos, apresentando VC de crescimento de $12,3 \mathrm{~cm} / \mathrm{a}$ no primeiro ano de tratamento, com altura adulta de 167,5 cm (Z da altura -1,0). Foi realizado reteste com ITT - 
apresentando resposta de GH de 6,7 ng/mL, indicando ausência de deficiência na fase adulta.

Neste paciente, foi identificada uma variante missense, presente em heterozigose no gene GHSR c. 545 T>C (p.Val182Ala) - classificada como variante de significado incerto - confirmada em sua irmã e pai com fenótipos normais e em seu filho, atualmente em investigação para atraso constitucional do crescimento e desenvolvimento, em outro serviço. Os dados de frequência e previsão in silico estão detalhados na Tabela 6.

Esta mesma variante no gene GHSR foi identificada na paciente 7, nascida de pais não consanguíneos, prematura (24 semanas) em razão de amioniorrexe prematura, nascida de parto pélvico vaginal, 935g. Esta paciente apresentou complicações ao nascimento e permaneceu internada por 3 meses na UTI neonatal. Procurou atendimento aos 7,6 anos, com altura de $95 \mathrm{~cm}$ (Z da altura -4,8) e IO de 3,5 anos. A paciente apresentava IGF-1 não detectável e foi realizado teste de estímulo com clonidina com pico de GH de 4,2 ng/ml. Recebeu rGH dos 7,6 aos 18,6 anos, atingindo estatura final de $146 \mathrm{~cm}$ ( $\mathrm{Z}$ da altura -2,7). Aos 9,9 anos, evoluiu com puberdade espontânea e, aos 10,5 anos, foi iniciado bloqueio de puberdade com análogo de GnRH que foi suspenso aos 12,6 anos. Aos 7,6 anos, foi identificada deficiência de TSH, iniciando reposição com levotiroxina.

Nesta paciente, em estudo prévio realizado em nosso serviço, foi identificada uma variante missense em heterozigose no gene GLI2 c.2798G>A (p.Arg933His) ${ }^{\text {[23] }}$. Como pacientes com variantes no GLI2 apresentam um padrão de herança dominante com penetrância incompleta, sugerindo a presença de um segundo fator para explicar o fenótipo, a paciente foi encaminhada para estudo genético no painel. É interessante 
ressaltar que a variante no GLI2 não foi identificada na primeira análise do painel em razão de baixa cobertura nesta região e foi necessária uma busca ativa no IGV (Integrative Genome Browser) para localizá-la (Figura 7). Na avaliação familiar, as mesmas variantes no GLI2 e GHSR estavam presentes em sua mãe com baixa estatura (Z da altura -2,4) e ausentes em sua irmã não afetada. A paciente apresenta história de uma tia com polidactilia, porém a análise de seu DNA não foi realizada.

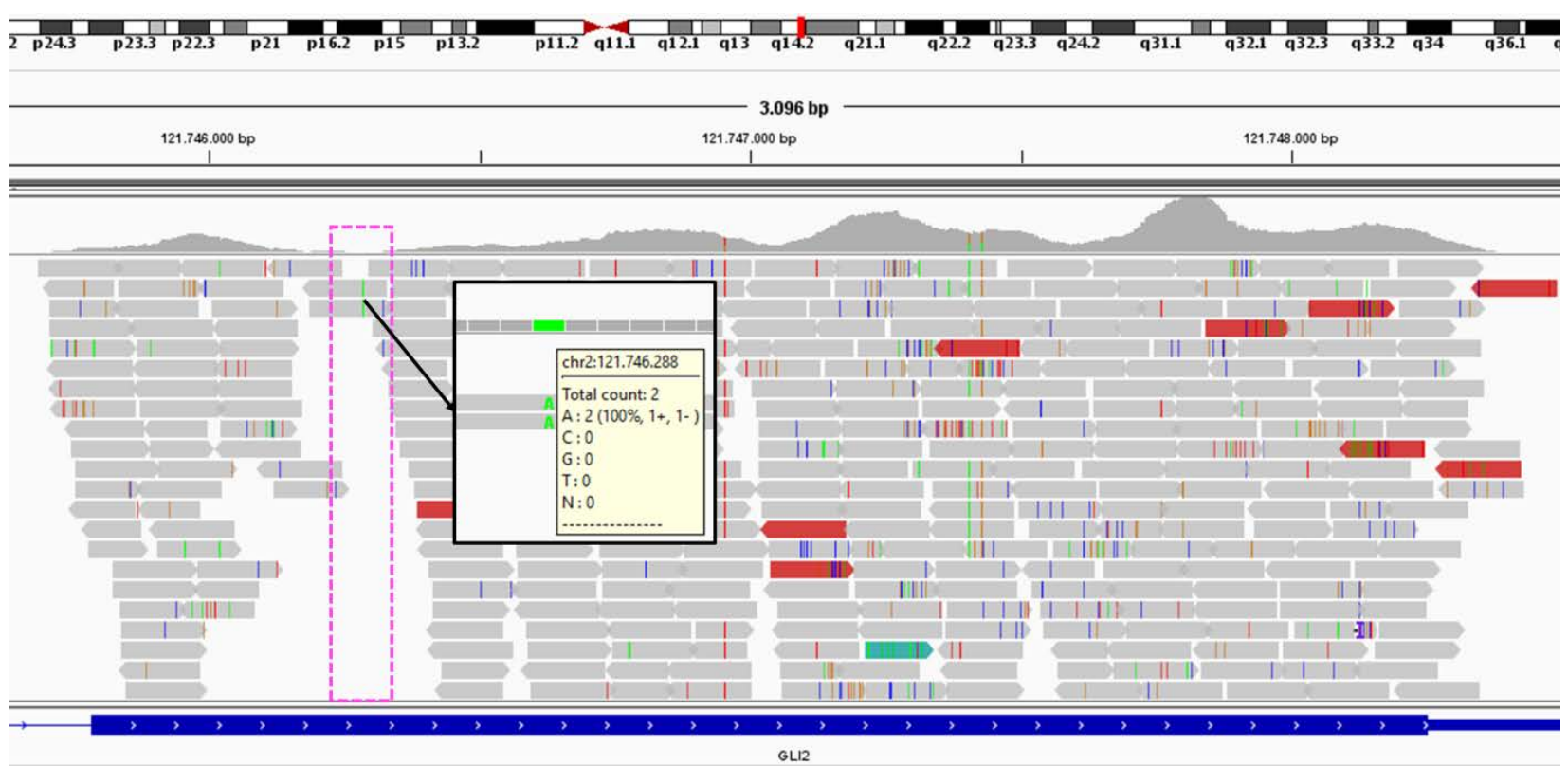

Figura 7 - Visualização das variantes encontradas no gene GLI2 no programa IGV (Integrative Genomics Viewer). Cada barra cinza corresponde a uma "read" (uma vez em que aquela região foi sequenciada) e observa-se que a região destacada em rosa foi lida apenas duas vezes. A variante missense gene GLI2 é representada pela presença de duas cores, o que significa que aquela região foi lida como adenina (A) (cor verde) no lugar de guanina $(G)$ 


\subsubsection{Paciente com a variante TGIF1 c.82T> C}

O paciente 8, sexo masculino, nasceu de pais não consanguíneos a termo com $3.850 \mathrm{~g} \mathrm{e} 48 \mathrm{~cm}$. Seu desenvolvimento neuropsicomotor foi normal. Iniciou acompanhamento aos 4,9 anos de idade, com uma altura de 86,7 cm ( $\mathrm{Z}$ da altura -5,5) com IO = 2,5 anos. Realizou um teste de clonidina e ITT, apresentando pico de GH de 0,4 ng/mL. Aos 8,6 anos, foi retestado com novo ITT, com uma resposta de GH de 0,1 ng/mL e cortisol de 7,2 $\mu \mathrm{g} / \mathrm{dL}$ (basal de 8,0 $\mu \mathrm{g} / \mathrm{dL}$ ). Recebeu reposição de rGH de 5 a 19 anos, com uma velocidade de crescimento no primeiro ano de tratamento de 12 cm/ano - atingindo uma altura final de 168,5 cm ( $\mathrm{Z}$ da altura -0,62). Foi iniciada reposição com acetato de hidrocortisona aos 9,1 anos, quando apresentou um cortisol basal de 6,0 $\mu \mathrm{g}$ / dL e reposição com levotiroxina aos 12,6 anos. RM de hipófise demonstrou ausência de parênquima hipofisário, haste interrompida e NHE.

A nova variante TGIF1 c.82T> C, uma troca de serina por prolina no códon 28 em heterozigose, foi encontrada no caso índice, em sua mãe e em um irmão não afetados. Os dados de frequência e previsão in silico estão detalhados na Tabela 6 . 
Tabela 6- Variantes de significado incerto de interesse identificadas pelo painel de genes em uma coorte de 117 pacientes com hipopituitarismo congênito

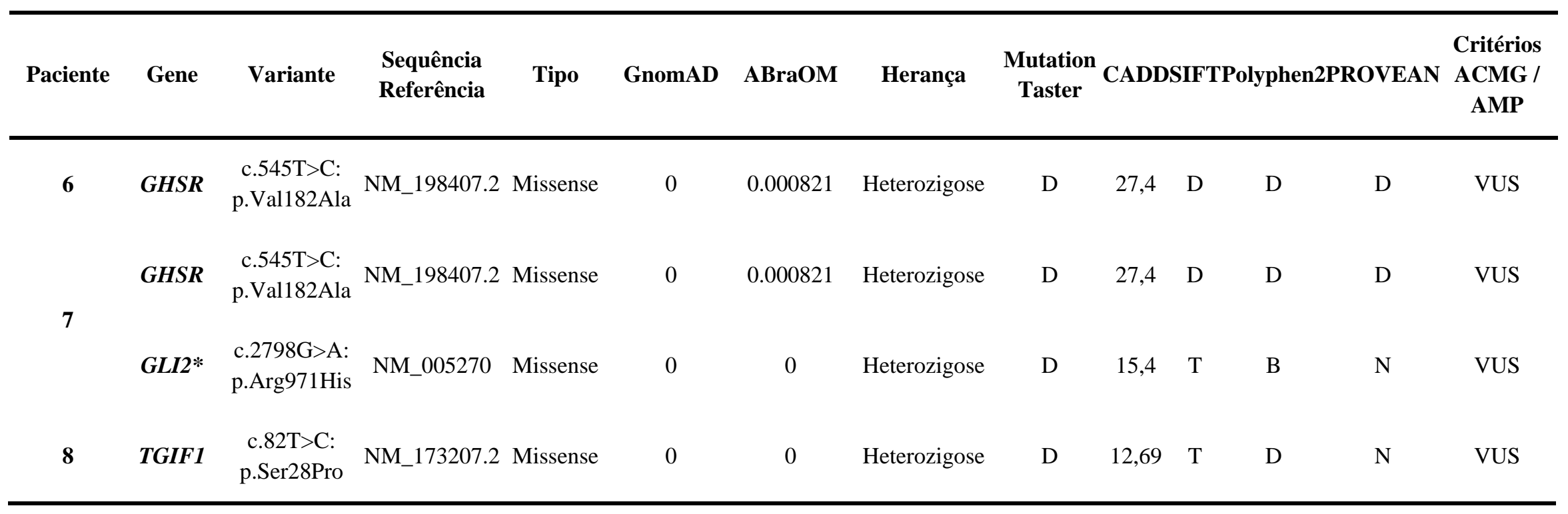

B - benigno; $\mathbf{T}$ - tolerada; $\mathbf{D}$ - deletério; $\mathbf{N}$ - neutro

* Esta variante nesta paciente foi identificada em estudo prévio realizado em nosso serviço ${ }^{[16]}$ 
5 Discussão 


\section{DISCUSSÃO}

Neste estudo, foram sequenciados 26 genes por meio de sequenciamento paralelo em larga escala - painel de genes - de forma simultânea em uma coorte de 117 pacientes com hipopituitarismo congênito. Foram identificadas seis variantes patogênicas responsáveis pelo fenótipo de hipopituitarismo congênito em cinco pacientes (taxa positividade de 4\%) em quatro genes GLI2, OTX, PROP1 e GHRHR.

\subsection{VARIANTES PATOGÊNICAS}

A nova variante do tipo nonsense no gene GLI2 (p.Glu561*) prediz uma proteína truncada com perda dos domínios de dedo de zinco e transativação no caso de escapar de degradação do RNA mensageiro. As variantes no GLI2 têm penetrância incompleta e podem levar a defeitos da linha média complexos, holoprosencefalia (HPE), fenda palatina, polidactilia e DHHM com fenótipos variáveis ${ }^{[29]}$. O paciente apresenta um fenótipo leve, com apenas DIGH, NHE e ausência de outras malformações craniofaciais.

A variante nonsense identificada no gene OTX2 (p.Gln107*) no estado heterozigoto, identificada pela primeira vez neste painel, caso traduzida, resultaria em uma proteína truncada com a perda de 190 aminoácidos. As variantes do OTX2 foram associadas a malformações oculares graves, como anoftalmia, microftalmia e graus variáveis de DHHM ${ }^{[4]}$. A maioria dos pacientes com mutações no OTX2 também 
apresenta anomalias cerebrais, convulsões e/ou atraso no desenvolvimento neuropsicomotor, o último também presente em nosso paciente.

Em relação às variantes no gene PROP1 [c.301_302delAG];[c.109+1G>A]: a deleção c.301_302delAG é a variante com maior prevalência no mundo em razão do de efeito fundador ${ }^{[30]}$; a variante c.109+1G>A foi encontrada pela primeira vez por este painel e, recentemente, publicada como uma nova variante por nossa Unidade em uma coorte de pacientes brasileiros com neuro-hipófise tópica (NHT) e DHHM ${ }^{\text {[33] }}$. Embora a presença de variantes no gene $P R O P 1$ seja maior nos casos familiares e consanguíneos, o paciente aqui descrito é um caso esporádico e o único membro afetado de sua família. Este paciente apresentava deficiência combinada de GH, LH/FSH e desenvolveu tardiamente a deficiência de ACTH aos 23,5 anos que, assim como descrito anteriormente, se desenvolve mais tardiamente ${ }^{[36,77]}$.

Foram encontradas duas variantes em homozigose do tipo nonsense no gene GHRHR em dois pacientes, ambos com fenótipo de DIGH. A primeira variante - uma inserção levando a um frameshift - foi descrita pela primeira vez no presente estudo e a segunda, uma variante afetando uma região canônica de sítio de splicing GHRHR c.57+1G > A, inicialmente foi relatada em uma grande comunidade com DIGH na cidade de Itabaianinha no Nordeste do Brasil. Sua maior prevalência no país ocorre pela presença de um fenômeno de gene fundador ${ }^{[24]}$. A maioria dos pacientes com DIGH com modo de herança autossômico recessivo tem variantes no GHRHR, sendo, portanto, um dos primeiros genes candidatos a serem rastreados em casos consanguíneos. 


\subsection{VUS DE INTERESSE}

Foram selecionadas duas variantes de significado incerto nos genes GHSR e TGIF1.

Mutações no gene GHSR foram implicadas na etiologia da baixa estatura, sendo associadas tanto com ACCD como com DIGH ${ }^{[19,78]}$. Em nossa casuística, foi identificada a variante do tipo missense em heterozigose GHSR c.545T>C (p.Val182Ala), prevista como deletéria em cinco programas de predição in silico. Esta variante está ausente no banco de dados GnomAD e presente no banco de dados brasileiro com uma frequência de 1/1.218 alelos, e foi previamente publicada no estudo de Pugliese et al. associada à ACCD demonstrando redução de 50\% da atividade basal em comparação à variante selvagem, o que se correlacionou com diminuição da expressão na superfície celular ${ }^{[19]}$. Diferentemente do estudo publicado, na família aqui descrita, a variante não segregou perfeitamente com o fenótipo (irmã e pai carreadores sem deficiências hormonais). No entanto, em estudos anteriores foi descrita penetrância incompleta neste gene, bem como a variabilidade fenotípica ${ }^{[78]}$. Por esses motivos, acredita-se que essa variante possa estar envolvida com o fenótipo de nosso paciente.

O TGIF1 atua como um repressor transcricional essencial no desenvolvimento do eixo neural durante o desenvolvimento do prosencéfalo ventral, regulando a via de sinalização Shh, sendo crucial para a bifurcação do prosencéfalo humano e formação de estruturas da linha média. Variantes com perda de função foram identificadas pela primeira vez, como causa de holoprosencefalia em humanos por Gripp et al. em $1998^{[79]}$. O único relato de uma variante desse gene c.799C>T, (p.Gln267*), como 
causa de DHHM, foi descrito por Tatsi et al. ${ }^{[80]}$, em paciente com deficiência de GH, TSH e LH / FSH, incisivo único central e PSIS (Pituitary Stalk Interruption Syndrome). A variante em heterozigose, identificada no gene TGIF1 c.82T>C (p.Ser28Pro) em nossa casuística, afeta o mesmo códon de uma mutação missense relatada anteriormente TGIF1 c.83C > T (p.Ser28Cys), encontrada em um paciente com defeitos na linha média sem hipopituitarismo. Estudos funcionais realizados por Gripp et al ${ }^{[79]}$. demonstraram que a proteína p.Ser28Cys diminui a repressão transcricional dependente de RXR (receptor de ácido retinóico) e TGF $\beta$ (transforming growth factor beta) e perde a capacidade de repressão via CtBP (C-terminal-binding protein 1 ). Dessa forma, embora classificada como VUS, a localização da variante e a presença de fenótipo semelhante ao anteriormente descrito sugerem a possibilidade de que a referida variante possa estar envolvida na etiologia do hipopituirarismo de nosso paciente.

Até o momento, apenas um estudo utilizou um painel de gene alvo para o diagnóstico de uma coorte de pacientes com HC. Foram estudados 51 pacientes de 44 famílias não relacionadas. A mesma mutação heterozigótica no gene GH1 (p.209Arg>His) foi identificada em duas famílias com o fenótipo de DIGH ${ }^{\text {[81] }}$. Outros estudos utilizaram painel de genes ou exoma para estudar pacientes com baixa estatura por diferentes etiologias, incluindo poucos pacientes com DGH. Dauber et al. ${ }^{[82]}$, estudaram 1.077 genes em 192 pacientes (31 com DHHM) e encontraram quatro variantes patogênicas nos genes PTPN11 e IGF1R (nenhum paciente com DHHM). Hauer et al. ${ }^{[83]}$ sequenciaram 200 pacientes com baixa estatura que foram submetidos a extensa avaliação clínica e endocrinológica para excluir defeitos na via do hormônio de crescimento e identificaram uma variante no gene GHSR. 
Como limitações do estudo atual, destaca-se que a maioria dos pacientes já havia sido avaliada para algum defeito genético em genes classicamente associados ao HC, porém pelo método de Sanger, o que provavelmente tenha implicado em uma menor taxa de resultados positivos.

O diagnóstico de deficiência de GH é complexo e, geralmente, envolve estudos auxológicos, hormonais e de imagem. A modesta taxa positiva de triagem genética de HC obtida com painéis genéticos indica que essa ferramenta genética ainda não pode substituir completamente o diagnóstico clínico.

Nos casos em que o paciente apresente um quadro clínico que, classicamente, aponte para uma causa frequente como, por exemplo, DHHM com neuro-hipófise tópica, que é fortemente associada a defeitos genéticos no $P R O P 1$, a abordagem de gene candidato pode ser efetiva.

No entanto, a dificuldade de correlação precisa genótipo-fenótipo na maioria dos pacientes com HC indica que o painel de genes oferece vantagens no diagnóstico genético, uma vez que se pode estudar inúmeros genes simultaneamente com precisão. 
6 Conclusões 


\section{CONCLUSÕES}

1. Um painel de genes associados ao hipopituitarismo congênito para sequenciamento paralelo em larga escala foi confeccionado com sucesso.

2. Em uma coorte de 117 pacientes com hipopituitarismo congênito foram encontradas seis variantes patogênicas em cinco pacientes (4\%), incluindo novas variantes nos genes GLI2, OTX2, PROP1 e GHRHR.

3. A correlação genótipo-fenótipo nos pacientes com variantes patogênicas e suspeitas para patogenicidade permitiu expandir o número de variantes e o quadro clínico relacionado a estes genes

4. O sequenciamento paralelo em larga escala de um painel de genes para hipopituitarismo congênito é um método útil para rastrear simultaneamente variantes de relevância biológica e clínica para a deficiência congênita de GH. 
7 Anexos 
Anexo 1 - 16 variantes de significado incerto, identificadas pelo Painel de Genes em uma coorte de 117 pacientes com hipopituitarismo congênito

\begin{tabular}{|c|c|c|c|c|c|c|c|c|}
\hline Gene & Variante & Sequência Referência & GnomAD & ABraOM & MutationTaster & GERP & SIFT & PROVEAN \\
\hline ARNT2 & $\begin{array}{l}\text { c.1066A }>\text { G } \\
\text { p.Ser356Gly }\end{array}$ & NM_014862 & 0 & 0 & $\mathrm{D}$ & 5,02 & $\mathrm{~T}$ & $\mathrm{~N}$ \\
\hline FGF8 & $\begin{array}{c}\text { c.G127T } \\
\text { p.Gly43Cys }\end{array}$ & NM_033163.3 & 0 & 0 & $\mathrm{D}$ & 2,84 & $\mathrm{~T}$ & $\mathrm{~N}$ \\
\hline FGFR1 & $\begin{array}{c}\text { c.G566A } \\
\text { p.Arg189His }\end{array}$ & NM_023110.2 & 0,00006092 & 0 & $\mathrm{D}$ & 5,56 & $\mathrm{~T}$ & $\mathrm{~N}$ \\
\hline GH1 & $\begin{array}{c}\text { c.134G >A } \\
\text { p.Arg45His * }\end{array}$ & NM_000515.3 & 0,0001 & 0 & $\mathrm{D}$ & 1,77 & $\mathrm{~T}$ & $\mathrm{~N}$ \\
\hline GHRH & $\begin{array}{c}\text { c.89G }>\text { A } \\
\text { p.Arg30Gln }\end{array}$ & NM_021081.4 & 0.000012 & 0 & $\mathrm{~N}$ & $-2,62$ & $\mathrm{~T}$ & $\mathrm{~N}$ \\
\hline GHRHR & $\begin{array}{l}\text { c.20C }>\text { T } \\
\text { p.Ala7Val }\end{array}$ & ENST00000409316.1 & 0.00002122 & 0 & $\mathrm{~N}$ & $-8,68$ & $\mathrm{D}$ & $\mathrm{D}$ \\
\hline GHRHR & $\begin{array}{c}\text { c. } 29 \mathrm{~T}>\mathrm{G} \\
\text { p.Val10Gly }\end{array}$ & NM_000823 & 0,0002 & 0 & $\mathrm{~N}$ & $-0,242$ & $\mathrm{D}$ & $\mathrm{N}$ \\
\hline GLI2 & $\begin{array}{c}\text { c.1106V }>C \\
\text { p.Val369Ala }\end{array}$ & NM_005270 & 0,0004 & 0 & $\mathrm{~N}$ & 4,81 & $\mathrm{~T}$ & $\mathrm{~N}$ \\
\hline GLI2 & $\begin{array}{c}\text { c.4729G >A } \\
\text { p.Glu1577Lys }\end{array}$ & NM_005270 & 0,00006465 & 0 & $\mathrm{D}$ & 4,98 & $\mathrm{D}$ & $\mathrm{D}$ \\
\hline KAL1 & $\begin{array}{c}\text { c.A31C } \\
\text { p.Thr11Pro }\end{array}$ & NM_000216.2 & 0 & 0 & $\mathrm{~N}$ & 0,505 & $\mathrm{~T}$ & $\mathrm{~N}$ \\
\hline
\end{tabular}


Anexo 1 - 16 variantes de significado incerto, identificadas pelo Painel de Genes em uma coorte de 117 pacientes com hipopituitarismo congênito (conclusão)

\begin{tabular}{|c|c|c|c|c|c|c|c|c|}
\hline Gene & Variante & Sequência Referência & GnomAD & ABraOM & MutationTaster & GERP & SIFT & PROVEAN \\
\hline KAL1 & $\begin{array}{l}\text { c.716C>G: } \\
\text { p.Thr239Arg }\end{array}$ & NM_000216.2 & 0 & 0 & $\mathrm{D}$ & 4,15 & $\mathrm{D}$ & $\mathrm{D}$ \\
\hline KAL1 & $\begin{array}{l}\text { c. } 911 \mathrm{~A}>\mathrm{G} \\
\text { p.Asn304Ser }\end{array}$ & NM_000216.2 & 0.000192 & 0 & $\mathrm{~N}$ & 4,11 & $\mathrm{~T}$ & $\mathrm{~N}$ \\
\hline PITX2 & $\begin{array}{l}\text { c. } 460 A>G \\
\text { p.Met154Val }\end{array}$ & NM_153427.2 & 0,0003 & 0 & $\mathrm{D}$ & 4,92 & $\mathrm{~T}$ & $\mathrm{~N}$ \\
\hline POU1F1 & $\begin{array}{c}\text { c.A370G } \\
\text { p.Met124Val }\end{array}$ & NM_000306.2 & 0,0026 & 0 & $\mathrm{D}$ & 4,46 & $\mathrm{~T}$ & $\mathrm{~N}$ \\
\hline PROP1 & $\begin{array}{c}\text { c.G675T } \\
\text { p.Trp225Cys }\end{array}$ & NM_006261.4 & 0 & 0 & $\mathrm{D}$ & 2,35 & $\mathrm{D}$ & $\mathrm{D}$ \\
\hline TGIF1 & $\begin{array}{c}\text { c.320A }>\mathrm{T} \\
\text { p.Gln107Leu }\end{array}$ & NM_173208.1 & 0.000322 & 0 & A & 4,25 & $\mathrm{~T}$ & $\mathrm{D}$ \\
\hline
\end{tabular}

* Encontrada em dois pacientes 
Anexo 2 - Critérios utilizados pela ACMG/AMP - Colégio Americano de Genética Médica e pela Associação de Patologia Molecular para classificação das variantes encontradas

\begin{tabular}{|c|c|c|c|}
\hline $\begin{array}{l}\text { Grupo de } \\
\text { Evidência }\end{array}$ & Abreviação & Significado & Grau de Evidência \\
\hline \multirow{5}{*}{$\begin{array}{l}\text { Frequência } \\
\text { Populacional }\end{array}$} & PS4 & $\begin{array}{l}\text { A prevalência da variante nos indivíduos afetados é significativamente maior quando comparada com a } \\
\text { prevalência em controles }\end{array}$ & $\begin{array}{c}\text { Forte para } \\
\text { patogenicidade }\end{array}$ \\
\hline & PM2 & $\begin{array}{l}\text { Variante ausente nos bancos de dados populacionais (1000Genomes, ExAC) (ou presente em frequência } \\
\text { extremamente baixa, para os casos recessivos) }\end{array}$ & $\begin{array}{l}\text { Moderado para } \\
\text { patogenicidade }\end{array}$ \\
\hline & BS1 & A frequência do alelo é maior que a esperada para a doença & $\begin{array}{l}\text { Forte para } \\
\text { benignidade }\end{array}$ \\
\hline & BS2 & $\begin{array}{l}\text { Variante para doença recessiva (em homozigose), dominante (em heterozigose) ou ligada ao X } \\
\text { (hemizigose), com penetrância completa e de início precoce, observada em indivíduo adulto saudável }\end{array}$ & $\begin{array}{l}\text { Forte para } \\
\text { benignidade }\end{array}$ \\
\hline & BA1 & Frequência alélica maior que 5\% nos bancos de dados populacionais (1000Genomes, ExAC) & Benigno por si só \\
\hline
\end{tabular}


Anexo 2 - Critérios ulitizados pela ACMG/AMP - Colégio Americano de Genética Médica e pela Associação de Patologia Molecular para classificação das variantes encontradas (continuação)

\begin{tabular}{|c|c|c|c|}
\hline $\begin{array}{l}\text { Grupo de } \\
\text { Evidência }\end{array}$ & Abreviação & Significado & Grau de Evidência \\
\hline \multirow{9}{*}{$\begin{array}{l}\text { Predição In } \\
\text { silico }\end{array}$} & PVS1 & $\begin{array}{l}\text { Variante nonsense, frameshift, em sítios de splice canônicos } \pm 1 \text { ou } 2 \text {, códon de iniciação ou deleção de } 1 \\
\text { ou vários exons (null variant) em um gene no qual variantes com perda de função (LoF) são mecanismos } \\
\text { conhecidos de doença }\end{array}$ & $\begin{array}{l}\text { Muito forte para } \\
\text { patogenicidade }\end{array}$ \\
\hline & PS1 & Troca de aminoácido já estabelecida como patogênica, independente da troca do nucleotídeo & $\begin{array}{c}\text { Forte para } \\
\text { patogenicidade }\end{array}$ \\
\hline & PM4 & $\begin{array}{l}\text { Modificação no tamanho da proteína causada por deleções ou inserções in-frame em região não repetitiva } \\
\text { ou por variantes que perdem o códon de parada (tipo stop-loss) }\end{array}$ & $\begin{array}{l}\text { Moderado para } \\
\text { patogenicidade }\end{array}$ \\
\hline & PM5 & $\begin{array}{l}\text { Nova variante missense em um aminoácido em que uma variante missense diferente já foi estabelecida } \\
\text { como patogênica }\end{array}$ & $\begin{array}{l}\text { Moderado para } \\
\text { patogenicidade }\end{array}$ \\
\hline & PP3 & $\begin{array}{l}\text { Várias ferramentas computacionais suportam a evidência de efeito deletério no gene ou proteína } \\
\text { (conservação evolutiva, impacto no sítio de splicing etc) }\end{array}$ & $\begin{array}{l}\text { “Supporting” para } \\
\text { patogenicidade }\end{array}$ \\
\hline & BP1 & $\begin{array}{l}\text { Variante missense em um gene no qual variantes com perda de função ( } L o F) \text { são mecanismos conhecidos } \\
\text { de doença }\end{array}$ & $\begin{array}{l}\text { Fraco para } \\
\text { benignidade }\end{array}$ \\
\hline & BP3 & Deleções ou inserções in-frame em região repetitiva sem função conhecida & $\begin{array}{l}\text { Fraco para } \\
\text { benignidade }\end{array}$ \\
\hline & BP4 & $\begin{array}{l}\text { Várias ferramentas computacionais sugerindo ausência de efeito deletério no gene ou proteína } \\
\text { (conservação evolutiva, impacto no sítio de splicing etc) }\end{array}$ & $\begin{array}{l}\text { Fraco para } \\
\text { benignidade }\end{array}$ \\
\hline & BP7 & $\begin{array}{l}\text { Variante sinônima cujas ferramentas de predição de dano a sítio de splicing não predizem impacto na } \\
\text { sequência consenso de splice nem a criação de um novo sítio, e o nucleotídeo não é conservado }\end{array}$ & $\begin{array}{c}\text { Fraco para } \\
\text { benignidade }\end{array}$ \\
\hline
\end{tabular}


Anexo 2 - Critérios ulitizados pela ACMG/AMP - Colégio Americano de Genética Médica e pela Associação de Patologia Molecular para classificação das variantes encontradas (conclusão)

\begin{tabular}{|c|c|c|c|}
\hline $\begin{array}{l}\text { Grupo de } \\
\text { Evidência }\end{array}$ & Abreviação & Significado & Grau de Evidência \\
\hline \multirow{4}{*}{$\begin{array}{l}\text { Estudos } \\
\text { Funcionais }\end{array}$} & PS3 & $\begin{array}{l}\text { Presença de estudos funcionais (in vitro ou in vivo) bem estabelecidos que suportem o efeito prejudicial no } \\
\text { gene ou sua proteína }\end{array}$ & $\begin{array}{c}\text { Forte para } \\
\text { patogenicidade }\end{array}$ \\
\hline & PM1 & $\begin{array}{l}\text { Variante localizada em uma região hotspot para mutações e/ou região importante já estabelecida com um } \\
\text { domínio funcional da proteína, sem variantes descritas como benignas }\end{array}$ & $\begin{array}{l}\text { Moderado para } \\
\text { patogenicidade }\end{array}$ \\
\hline & PP2 & $\begin{array}{l}\text { Variante missense em um gene com uma baixa taxa de mutações missense benignas e no qual esse tipo de } \\
\text { variante é considerado um mecanismo comum de doença }\end{array}$ & Apoia patogenicidade \\
\hline & BS3 & $\begin{array}{l}\text { Presença de estudos funcionais (in vitro ou in vivo) bem estabelecidos mostrando ausência de efeito } \\
\text { prejudicial para a proteína ou sítio de splicing }\end{array}$ & $\begin{array}{l}\text { Forte para } \\
\text { benignidade }\end{array}$ \\
\hline \multirow{2}{*}{ Segregação } & PP1 & $\begin{array}{l}\text { Segregação da variante (em um gene conhecido como causador de doença) com a doença em uma família } \\
\text { com vários membros afetados }\end{array}$ & $\begin{array}{l}\text { Moderado para } \\
\text { patogenicidade }\end{array}$ \\
\hline & BS4 & Ausência de segregação nos indivíduos afetados da família & $\begin{array}{l}\text { Forte para } \\
\text { benignidade }\end{array}$ \\
\hline \multirow{2}{*}{$\begin{array}{l}\text { Dados do } \\
\text { Alelo }\end{array}$} & PM3 & Variante detectada em trans com uma variante patogênica para as doenças recessivas & $\begin{array}{l}\text { Moderado para } \\
\text { patogenicidade }\end{array}$ \\
\hline & BP2 & $\begin{array}{l}\text { Variante detectada em trans com uma variante patogênica dominante com penetrância completa ou } \\
\text { observada em cis com uma variante patogênica em qualquer tipo de herança }\end{array}$ & $\begin{array}{l}\text { Fraco para } \\
\text { benignidade }\end{array}$ \\
\hline \multirow[b]{2}{*}{ Outros Dados } & PP4 & O fenótipo do paciente ou a história da família são bastante específicos de uma doença monogênica & Apoia patogenicidade \\
\hline & BP5 & Variante encontrada em um caso com uma base molecular alternativa para doença & $\begin{array}{l}\text { Fraco para } \\
\text { benignidade }\end{array}$ \\
\hline Dado Artefato & -- & $\begin{array}{l}\text { Artefato de sequenciação conforme determinado por profundidade, qualidade ou outros dados previamente } \\
\text { revisados }\end{array}$ & -- \\
\hline
\end{tabular}


ANEXO 3 - PUBLICAÇÃO

$\begin{aligned} & \text { S. Endocrine } \\ & \text { CONNECTIONS5 }\end{aligned}$
RESEARCH Nakaguma et al.
RES

\section{Genetic diagnosis of congenital hypopituitarism by a target gene panel: novel pathogenic variants in GLI2, OTX2 and GHRHR}

Marilena Nakaguma', Fernanda A Correa', Lucas S Santanaz', Anna F F Benedetti', Ricardo V Perez".

Martha K P Huayllas', Mirta B Mirass, Mariana F A Funari', Antonio M Lerarioł, Berenice B Mendonca'.

Luciani R S Carvalho', Alexander A L Jorge² and Ivo J P Arnhold'

"Unidade de Endocrinologia do DeserwolMmenta, Laboratb́rio de Hormónios e Genética Molecular Li M42, Dibcipina de Endocrinologla, Hospital das Clinicas da Faculdade de Medicina da Universilade de SSO Paulo, Sso Pasla, Brasil

IUnidade de Endocrinologia Gentetica, Laboratbrio de Endocrinologla Celular e Molecular UM25, Disdiplina de Endocrinologia, Hospltal das Cilinicas da Faculdade de Medidina da Universidade de Sso Paulo, Sso Paulo, Bracl

"Serviço de Endocrinologia, Hospital do Senvidor Público Estadual de SSo Paulo, Instrtuto de Assizztnda Módica ao Senvidor Público Estadual (HSPE. IAMSPE, SSO Paulo, Brasil

"Hospital de Traneplantes Euryclides de Jesus Zerbini Sso Paulo, Brasl

"Hospital de Ninos Santisima Tininidad, Cordoba, Argentina

"Department of internal Medicine, Devision of Metabolism, Endocrinology and Dlabetes, Universihy of Michigan, Ann Arber, Michigan, USA

Correspondence should be addressed to IJ P Amhoid: lamholdeusp.br

\section{Abstract}

Aim. Congenital hypopituitarism has an incidence of 1:3500-10,000 births and is defined by the impaired production of pituitary hormones. Early diagnosis has an impact on management and genetic counselling. The clinical and genetic heterogeneity of hypopituitarism poses difficulties to select the order of genes to analyse. The objective of our study is to screen hypopituitarism genes (candidate and previously related genes) simultaneously using a target gene panel in patients with congenital hypopituitarism. Methods: Screening of 117 subjects with congenital hypopituitarism for pathogenic variants in 26 genes associated with congenital hypopituitarism by massively parallel sequencing using a customized target gene panel.

Results: We found three novel pathogenic variants in OTX2 c.295C-T:p.GIn99* GLI2 c.1681G T:P.Glu561* and GHRHR c.820_821insC.p.Asp274Alafs*113, and the previously reported variants in GHRHR c.57+1G×A and PROP1 [c.301_302delAG]:[c.109+1G>A]. Condusions: Our results indicate that a custom-designed panel is an efficient method to screen simultaneously variants of biological and clinical relevance for congenital GH deficiency. A genetic diagnosis was possible in 5 out of 117 (4\%) patients of our cohort We identified three novel pathogenic variants in GHRHR, OTX2 and GLI2 expanding the spectrum of variants associated with congenital hypopituitarism.

Key Words

- congenital hypopituitarism

- growth hormone

deficiency

mutations

- massively paralle

sequending

- highthroughput

nucleotide sequencing

- target gene panel
Introduction

Congenital hypopituitarism $(\mathrm{CH})$ is a rafe disorder (incidence of 1:3500-10,000 births) defined by the deficiency of one or more pituitary hormones $(1,2)$. Clinical presentation varies, ranging from isolated growth hormone deficiency (IGHD) to combined

\begin{tabular}{|c|c|}
\hline 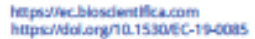 & 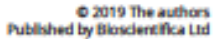 \\
\hline
\end{tabular}

pituitary hormone deficiencies (CPHD). CH also varies with respect to hypothalamic-pituitary anatomy from normal magnetic resonance imaging to the presence of midline defects such as pituitary stalk interruption syndrome (PSIS) and/or severe complex

intertupton syndrome (TSIS) and/or severe complex 


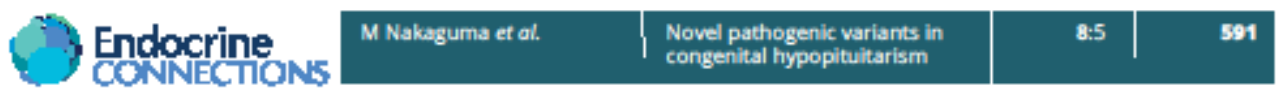

craniofacial malformations, such as septo-optic dysplasia (SOD).

The genetic defects leading to $\mathrm{CH}$ were classified in: defects in GH secretion (GHI, GHRHR); defects in pituitary cell differentiation (PROP1, POUIFI) and defects in pituitary development (such as HEXX1, GLI2, OTX2) (2). The most common genes implicated are those encoding GHI and GHRHR in IGHD and PROPI in CPHD, especially in certain geographical regions. Until now, most studies used the candidate-gene approach as the main strategy to identify the genetic cause of $\mathrm{CH}$ (3). As this strategy considers the patient's clinical presentation to guide the molecular investigation, genes were heterogeneously screened in most studies - the same genes were not analysed in the entire cohort. Moreover, as the clinical phenotype is highly variable, we cannot assure that all possible causative genes were excluded (4). The use of massive parallel sequencing, mostly targeted sequencing panel or whole exome sequence (WES), allows the screening of several genes simultaneously with high accuracy in a less time-consuming way.

In the present study, we developed a comprehensive gene panel for systematic assessment of $\mathrm{CH}$ including previously known and newly discovered genes related to $\mathrm{CH}$ in a large cohort with the objective of expanding the clinical and etiological spectrum of this disease.

\section{Patients and methods}

Patients with $\mathrm{CH}$ followed at the Unidade de Endocrinologia do Desenvolvimento (Sao Paulo, Brazil) and Hospital de Ninos Santisima Trinidad (Cordoba, Argentina) with previous positive genetic diagnosis by
Sanger sequencing with the candidate-gene approach were not included in this study. We selected 117 subjects with $\mathrm{CH}$ of unknown cause (104 from Brazil and 13 from Argentina) (Fig. 1). The patients were predominantly male $(55 \%, n=64)$, only eight were born from consanguineous parents and another 25 had relatives with short stature. Most of them had CPHD $(77 \%, n=90)$ and ectopic posterior pituitary (EPP) lobe $(68 \%, n=79)$ (Fig. 1). The median age of the first visit was 11 years (ranging from 6 days to 51.9 years), height SDS of -3.8 (ranging from -1.8 to -7.4 ) and GH peak of $1.7 \mu \mathrm{g} / \mathrm{dL}$ (ranging from undetectable to $4.7 \mathrm{\mu g} / \mathrm{dL}$ ). This study was approved by the respective Local Ethics Committees ("Comitê de Ética para Análise de Projetos de Pesquisa' in Brazil and 'Comité Institucional de Ética de la Investigación en Salud del Nino y del Adulto' in Argentina) and the patients or guardians gave their written informed consent.

Serum levels of TSH, GH, LH, FSH, PRL, cortisol, dehydroepiandrosterone sulphate, total thyroxine, free thyroxine, insulin-likegrowth factor 1 (IGF-1), oestradiol or testosterone levels were measured at baseline. Stimulatory tests were performed for the diagnosis of $\mathrm{GH}$ and other pituitary hormone deficiencies as previously described (5). In neonates, GH (cut-off limit $<5 \mathrm{ng} / \mathrm{mL}$ ) deficiency was evaluated considering the baseline $\mathrm{GH}$ measurement during hypoglycaemia and IGF-1 and IGFBP-3 levels less than -2 SDS for age and sex. As patients were studied at different centres using different hormonal assays, normal ranges of each centre were considered.

\section{Target gene panel}

Genomic DNA was extracted from peripheral blood leucocytes of all patients. A customized gene panel was

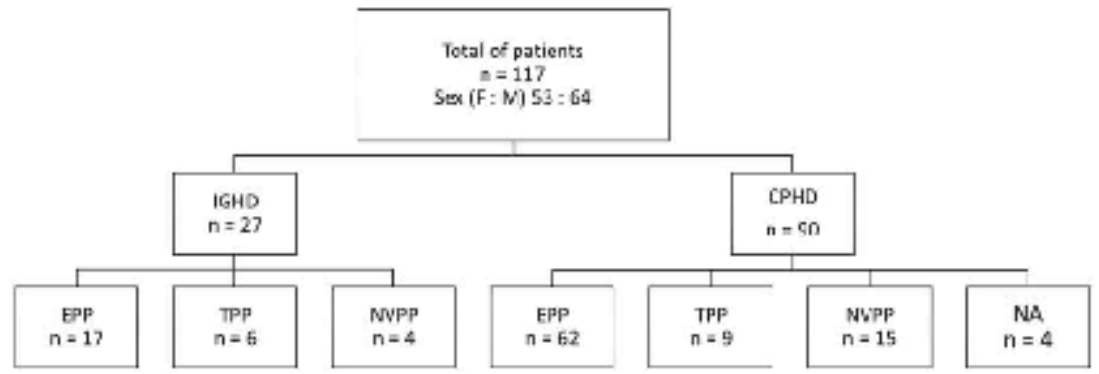

Flgure 1

Clinical features of sequenced patients. CPHD, combined pitutary hormone defidency, EPP, ectopic posterior pitultary lobe; IGHD, isolated growth hormone deficlency, NA not avaliable; NVP, non-visualized posterior pituitary, TPP, topic posterior pitultary lobe.

\begin{tabular}{|c|c|}
\hline 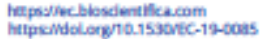 & 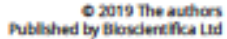 \\
\hline
\end{tabular}




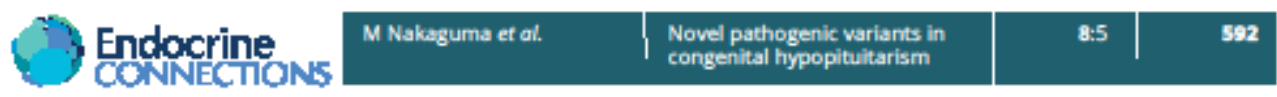

designed using Agilent Sure Design (Agilent Technologies, Inc.) with probes for 26 genes previously related to hypopituitarism GH1, GHRH, GHRHR, GHSR, PROP1, POU1F1, GLL2, HESX1, LHX3, LHX4, OTX2, PITX2, ARNT2, DMXI2, FGF8, FGFR1, GPR161, HHIP, IGSF1, KAL1, PROKR2, RNPC3, SHH, SOX2, SOX3 and TGIF1 (2).

Genomic DNA was mechanically fragmented using Covaris. Libraries were constructed using SureSelect Target Enrichment System Technology in accordance with the manufacture's protocols (Agilent Technologies). The sequences were generated in the Illumina NextSeq 500 platform running on paired-end mode. Reads were aligned to the GRCh37/hg19 assembly of the human genome with the Burrows-Wheeler aligner (BWA-MEM) (GNU General Public License version 3.0 (GPLv3), MIT License, Cambridge, MA, USA). Variant calling was performed with Freebayes (https://wiki.gacrc.uga.edu/wilk//Freebayes) and the resulting variant call formats (VCFs) were annotated with ANNOVAR (http://annovar.openbioinformatics.ong/ en/latest/).

The targeted panel sequencing data were screened for fare variants (MAF $<1 \%$ ) in public global and Brazilian databases: gnomAD (https//gnomad.broadinstitute. org/) and $\mathrm{ABraOM}$ (http://abraom.lb.usp.br/), located in exonic regions and consensus splice site sequences. Next, our variant filtration prioritized genes based on their potential to be pathogenic: loss-of-function (LoF) variants and variants predicted to be pathogenic by multiple in silico programmes (SIFT, PolyPhen2, Mutation Taster, PROVEAN and CAAD). The sequencing reads carrying candidate variants were inspected visually using the Integrative Genomics Viewer (IGV) to reduce false-posittve calls. Sanger sequencing confirmed all pathogenic and probably pathogenic variants. (Primer sequence and amplification protocols are available upon request.) The variants at the final list were assessed for the clinical interpretation of pathogenicity using InterVar (http://wintervar.wglab.org/) according to the American College of Medical Genetics and Genomics/ Association for Molecular Pathology (ACMG/AMP) variant pathogenicity guidelines (6).

\section{Results}

Molecular results

The median coverage depth of the coding regions in our panel data was $462 x$, with at least $99.6 \%$ of the sequenced bases covering more than 20 -fold.

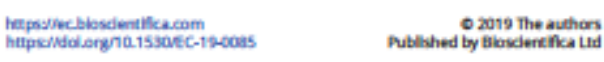

We identified causative pathogenic variants in 5 of $117 \mathrm{CH}$ patients (diagnostic yield of $4 \%$ ) (Table 1). These variants were in genes directly involved in $\mathrm{GH}$ secretion (GHRHR), in pituitary cell differentiation (PROP1) and in pituitary development (GLI2, OTX2). All variants were absent or extremely rare in local and public databases (Table 1).

Ballelic LoF variants were identified in GHRHR and PROP1 genes. One pathogenic mutation located in a consensus splice site (c.57+1G>A) and another causing a frameshift mutation (c.820_821insC:p.Asp274Alafs*113) in GHRHR were found in homozygous state, each in one patient with IGHD. Two pathogenic variants in PROPI were identified in compound heterozygous state in one patient with CPHD by this panel and has been recently published with a cohort of PROPI Brazilian patients (7).

Two novel heterozygous nonsense pathogenic variants were identified in GL.J2 (c.1681G>T:p.Glu561*) and OTX2 (c.295C>T:p.Gln99*), each one in one subject.

\section{Phenotype of subjects with variants of interest}

Characteristics of affected subjects are detailed in Table 2. Weight, length at birth, GH peak, age and height SDS at first visit did not differ significantly from those with negative molecular results. All patients were severely affected at presentation (median height SDS of -5.8 , ranging from -7.8 to -4.4 ) (Table 2 ).

Among the patients with homozygous variants in GHRHR, one patient was born to consanguineous parents and the other patient's parents came from the same small village and probably presented some degree of consanguinity. The second case had a short brother and the presence of the same variant was identified in homozygous state by Sanger sequencing.

The patients carrying variants in GHRHR had IGHD and topic posterior pituitary (TPP). The patient with PROP1 mutation had CPHD (GH, TSH and partial ACTH deficiencies) and TPP.

Patients with pathogenic variant in genes precociously expressed during hypothalamic-pituitary development, GLI2 and OTX2, presented IGHD and EPP.

The mother of the patient with GLI2 variant, also carrying the same mutation, has short stature $(-4.0$ HSDS), EPP, hypoplasia of anterior pituitary and thin stalk, despite having IGF-1 levels in the normal range for her advanced age. The index patient's mother referred that her brother and nephew (not available for clinical or genetic studies) had polydactyly. 


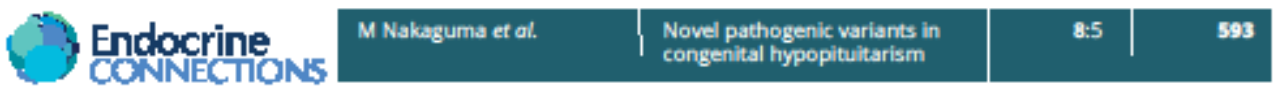

Table 1 Pathogenic variants identified by targeted panel sequencing in a cohort of 117 patients with congenital hypopituitarism.

\begin{tabular}{|c|c|c|c|c|c|c|c|c|}
\hline Pattlent & Gene & Allellic varlant & Gnomad & ABraom & Inheritance & $\begin{array}{l}\text { Evidence of } \\
\text { pathogeniclity } \\
\text { according to } \\
\text { ACMG/AMP }\end{array}$ & $\begin{array}{l}\text { Final ACMG/AMPP } \\
\text { classiflentlon } \\
\end{array}$ & Refseq id \\
\hline 1 & GHRHR & $C .57+10 \times A$ & 0.00001957 & 0 & Homozygous & PVS1, PM2, PP3 & Pathogenic & $\begin{array}{l}\text { NM_o00823.3 } \\
\text { rs2302022 }\end{array}$ \\
\hline 2 & GHRHR & $\begin{array}{l}\text { C820_821insC: } \\
\text { p.Asp274Alafs*113 }\end{array}$ & 0 & 0 & Homozygous & PVS1, PM2, PP3 & Pathogenic & NM_000823.3 \\
\hline \multirow[t]{2}{*}{3} & PROP1 & $\begin{array}{l}\text { c.301_302del: } \\
\text { p.Leu102Cysfs } \star 8\end{array}$ & 0,0001805 & 0 & $\begin{array}{l}\text { Compound } \\
\text { Heterozygous }\end{array}$ & PVS1, PM1, PP5 & Pathogenic & $\begin{array}{l}\text { NM_006261.4 } \\
\text { rs193922688 }\end{array}$ \\
\hline & & $C 109+1 G>A$ & 0 & 0 & $\begin{array}{l}\text { Compound } \\
\text { Heterozygous }\end{array}$ & PVS1, PM2, PP3 & Pathogenic & NM_006261.4 \\
\hline 4 & GL/2 & c1681Q T:p.Glu561* & 0 & 0 & Heterozygous & PVS1, PM2, PP3 & Pathogenic & NM_005270.4 \\
\hline 5 & OTX2 & c.2950-T.p.GIn99* & 0 & 0 & Heterozygous & PSV1, PM2, PP3 & Pathogenic & NM_172337.2 \\
\hline
\end{tabular}

PVSI, null variant (nonsense, frameshift, canonical $\$ 1$ or 2 splice sitea, initistion codon, single or multiexon deletion) in a gene where Lof is a known mechanism of disesse, PM1, located in a mutational hot spot andior citical and wel-established functional domain (e.g. active site of an enzyme) withous benign variation; PM2, abeent from controts (or at extremely low frequency if recessive) in Exome Sequenchng Project, 1000 Genomes Project, or Exome Aggregation Coneortium, PP3, multiple ines of computational evidence support a deleterious effect on the gene product, PPS, reputable source recently

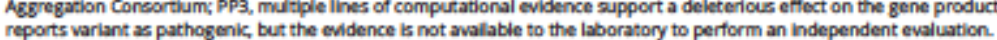

The patient carrying the mutation in OTX2 had microphthalmia, nystagmus and neuropsychomotor developmental delay.

\section{Discussion}

In this study, we screened simultaneously 26 genes in a cohort of 117 patients with $\mathrm{CH}$ using a target gene panel approach and identified five causative pathogenic variants (positive yield of $4 \%$ ) in genes GHRHR, PROP1, GLI2 and OTX2. A limitation of this study is that this cohort included, in addition to patients who were not sequenced before, patients in whom some candidate genes had been negative by Sanger sequencing. Therefore, a higher yield might be expected in a prospective cohort.

We found two null homozygous mutations in GHRHR in two patients and, as expected, both patients had IGHD with orthotopic posterior pituitary lobe. One variant was a frameshift insertion described for the first time in the present study and the other was a splicing mutation (c.57+1G>A) initially reported in a large kindred with isolated GH deficiency from Itabaianinha in Northeastem Brazil (8). The same variant in homozygous and compound heterozygous state was also previously described in other Brazilian familial and sporadic cases and a founder effect was demonstrated (9). Most patients with autosomal recessive IGHD have variants in GHRHR

Table 2 Clinical characteristics of patients with pathogenic variants.

\begin{tabular}{|c|c|c|c|c|c|c|c|c|}
\hline Patients & Gene & Sex & Dellvery & $\begin{array}{l}\text { Familly } \\
\text { history }\end{array}$ & $\begin{array}{l}\text { Helght SDS } \\
\text { at first visit }\end{array}$ & $\begin{array}{l}\text { Hormenal } \\
\text { definclency }\end{array}$ & Mara & $\begin{array}{l}\text { Asseclated complex } \\
\text { phenotype }\end{array}$ \\
\hline 1* & GHRHR & $\mathbf{F}$ & Caesarean section & No & -5.2 & IGHD & Normal & Deafness \\
\hline $2^{b}$ & GHRHR & $\mathbf{F}$ & Normal & $\begin{array}{l}\text { Affected } \\
\text { brother }\end{array}$ & -5.8 & IGHD & $\begin{array}{l}\text { Anterior pituitary } \\
\text { hypoplasia, NVPP }\end{array}$ & Absent \\
\hline 3 & PROP1 & M & Normal & No & -7.8 & GH, TSH, ACTHP & $\begin{array}{l}\text { Anterior pituitary } \\
\text { hypoplasia, TPP }\end{array}$ & Absent \\
\hline 4 & GU2 & M & $\begin{array}{l}\text { Caesarean section, } \\
\text { hemornhage } \\
\text { during labour }\end{array}$ & $\begin{array}{l}\text { Reported } \\
\text { short } \\
\text { stature }\end{array}$ & -4.4 & IGHD & EPP & Absent \\
\hline 5 & $O D C$ & M & Normal & No & -6.1 & IGHD & $\begin{array}{l}\text { EPP, septo-optic } \\
\text { dysplasia }\end{array}$ & $\begin{array}{l}\text { Microphthalmia, } \\
\text { mystagmus, } \\
\text { neuropsychomotor } \\
\text { developmental delay }\end{array}$ \\
\hline
\end{tabular}

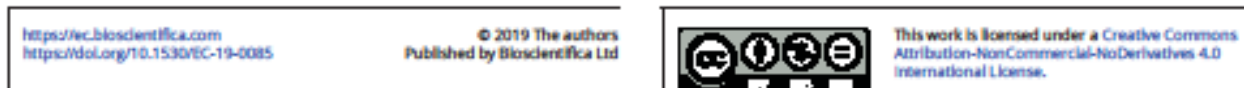




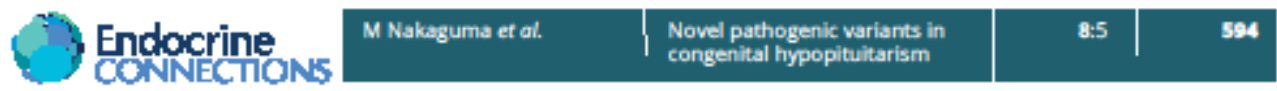

which is therefore one of the first candidate genes to be screened in consanguineous cases (10).

We found two pathogenic variants in compound heterozygous state in PROPI [c.301_302delAG];[c.109+1G>A] in one subject. Whereas c.301_302delAG is the most common PROP1 variant worldwide due to a founder effect, the $c .109+1 \mathrm{G}>$ A variant was first found by this panel and recently published as a novel variant by our Unit together within a cohort of Brazilian patients $(7,11)$. Although there is an increased prevalence of familial cases and consanguinity among patients with CPHD due to PROPI variants, the patient described here is a sporadic case and the only affected member of his family (7).

One patient in our cohort had a pathogenic stop codon variant in GLI2 (p.Glu561*) that predicts a truncated protein with loss of the zinc finger and transactivation domains. Variants in GLI2 have incomplete penetrance and can lead to complex midline defects, holoprosencephaly (HPE), cleft palate, polydactyly and CPHD with variable phenotypes (12, 13). Our patient presents a mild phenotype with only IGHD, and no craniofacial defects.

A novel nonsense variant was identified in $O T X 2$ (p.Gln107 ${ }^{\star}$ ) gene in heterozygous state, predicting a truncated protein with the loss of 642 amino acids. Variants in OTX2 were associated to severe ocula malformations such as anophthalmia, microphthalmia and variable degrees of hypopituitarism. Most patients with OTX2 mutations also exhibit brain anomalies and/or seizures that are not present in our case (14).

Until now, only one study used a target gene panel for the diagnosis of a cohort of patients with $\mathrm{CH}: 51$ patients from 44 independent pedigrees were evaluated for mutations using a target sequence panel, in which genes were captured using smMIPS (single-molecule molecular inversion probe capture assay). In two families with IGHD phenotype, the same heterozygous mutation in $G H 1$ gene (p_Arg209His) was identified (15).

Other studies used target panel or whole exome sequencing to study patients with short stature due to different etiologies including few patients with GHD. Dauber et al. sequenced 1077 genes in 192 patients (31 with CPHD) and found four pathogenic variants in PTPNII and IGFIR genes (16). Hauer et al. sequenced 200 patients with short stature who underwent extensive prior endocrinological and diagnostic workup to exclude defects of the growth hormone pathway and identified one variant in the GHSR gene (17). At last, another study performed exome-sequencing on ten patients with CPHD

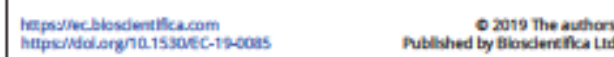

and their unaffected parents and suggested SLC2OA1 and SLC15A4 as new candidate genes (18).

Using a target gene panel in large cohorts allows the screening of many genes simultaneously with higher accuracy avoiding the misinterpretation caused by the lack of phenotype-genotype correlation. Therefore, we believe that this approach has advantages for the genetic diagnosis when compared to the candidate-gene approach.

The diagnosis of $\mathrm{GH}$ deficiency is complex and usually involves auxological, hormonal and imaging studies (19). If recent advances in genetic studies will curtail this diagnostic odyssey remains to be elucidated. The modest positive rate of genetic screening of $\mathrm{CH}$ ( $4 \%$ : this study) obtained with gene panels indicates that this genetic tool still cannot replace the clinical diagnosis of $\mathrm{CH}$.

We conclude that a custom-designed target gene panel is an efficient method to screen simultaneously variants of biological and clinical relevance for congenital $\mathrm{GH}$ deficiency. A genetic diagnosis was possible in 5 out of 117 (4\%) patients of our cohort. We identified novel variants in GHRHR, PROP1, OTX2 and GLI2. Further studies are necessary to understand the participation of other genetic, epigenetic phenomena and/or environmental factors in the aetiology of most patients with $\mathrm{CH}$.

\section{Declaration of interest}

The authors declare that there is no conflat of interest that could be perceived as prejudicing the impartialty of the research reported.

\section{Funding}

The National Coundl of Technological and Sclentitc Development (ONPq) - Brasil, supported this work grant number 305743/2011.2 to B8M and 301871/2016-7 to ANL, SSO Paulo Fesearch Foundation (FAPESP) also supported this work grant number $2013 / 03236.5$ to $A$ AL; 2015/26563.7 to LRC grant 2013/02162-8and grant SELA 2014/50137.5.

\section{References}

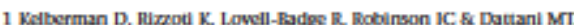
Cenetic regeulation of pitultary giand devisopment in human and mouse. Bndocthe hovicus 200930 790-829. (thitps://dol.org/10.1210/ er.2009-0005)

2 Fang Q George NS, Brinkmeier ML, Mortensen $\mathrm{AH}$, Gergics P, Cheung LY, Daly AZ, Ajmal A, Ferez Millan MI, Ond AB, ef at. Genetios of combined pitultary hormone deflicency: roodmap into

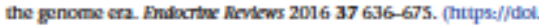
org/10.1210/er.2016-1101)

3 Crisafulli G, Avers T, Zirlll G, De lua E, Gallizal R \& Waniswak M. Congenital hypopitultarism: how to select the

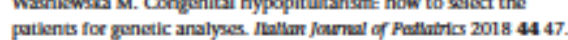
patients for genetic analyser. llathm foumal of

4 De Flenxo F, Mellone S, Bellone S, Babu D, Fusco L, Prodam F, Petri A, Muniswamy R, De Lua E, salerno M, et al. Frequency of grenstic 


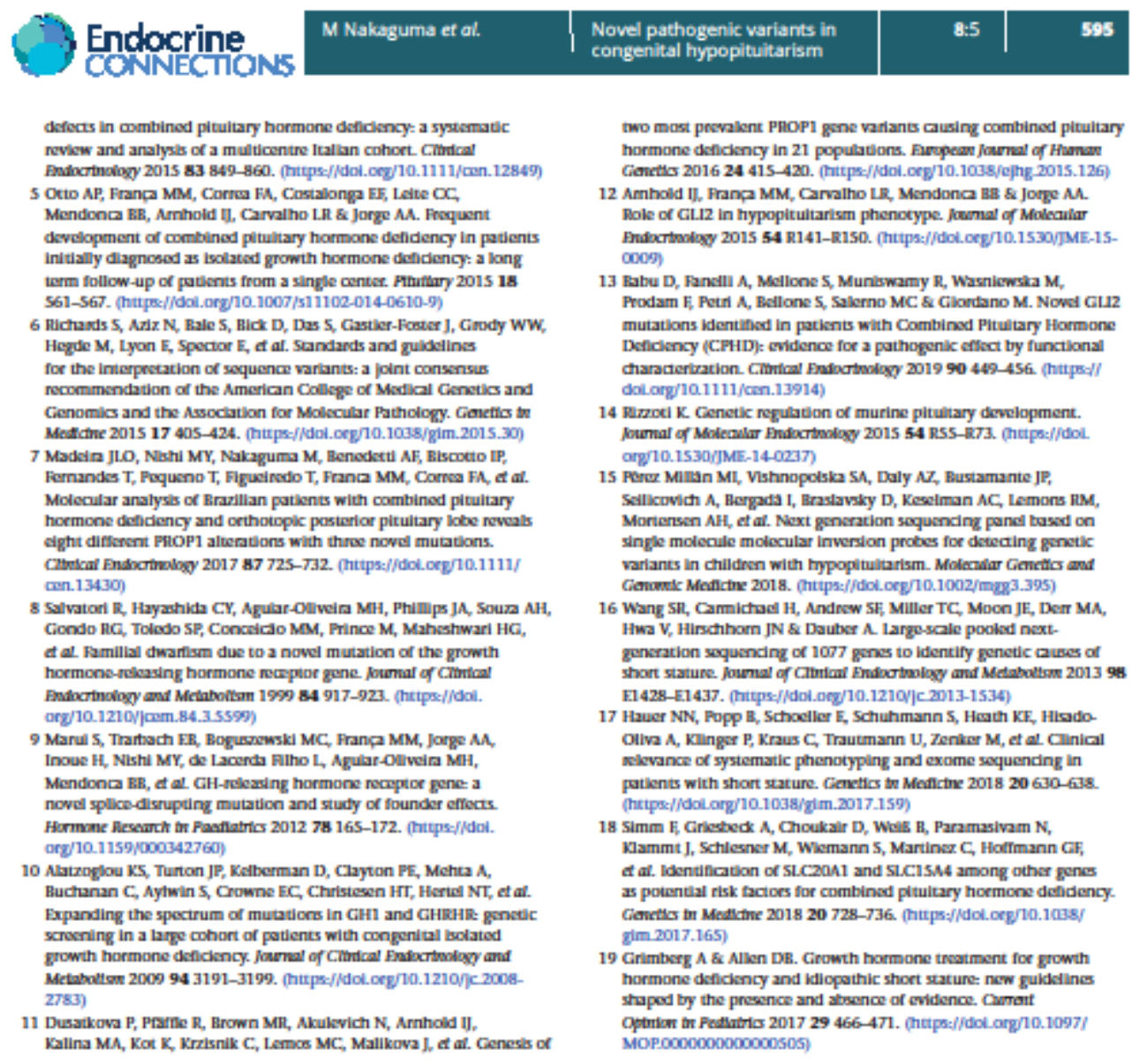

Recelved in final form 21 March 2019

Accepted 4 Apetl 2019

Accepted Preprint published online 4 April 2019 


\section{REFERÊNCIAS}

1. Kelberman, D., et al., Genetic regulation of pituitary gland development in human and mouse. Endocr Rev, 2009. 30(7): p. 790-829.

2. SBP, et al., Baixa Estatura por Deficiência do Hormônio de Crescimento: Diagnóstico. 2004: Projeto Diretrizes, Associação Médica Brasileira e Conselho Federal de Medicina.

3. Alatzoglou, K.S. and M.T. Dattani, Genetic causes and treatment of isolated growth hormone deficiency-an update. Nat Rev Endocrinol, 2010. 6(10): p. 562-76.

4. Fang, Q., et al., Genetics of Combined Pituitary Hormone Deficiency: Roadmap into the Genome Era. Endocr Rev, 2016. 37(6): p. 636-675.

5. Mendonca, B.B., et al., Longitudinal hormonal and pituitary imaging changes in two females with combined pituitary hormone deficiency due to deletion of A301,G302 in the PROP1 gene. J Clin Endocrinol Metab, 1999. 84(3): p. 942-5.

6. Arnhold, I.J., et al., Clinical and molecular characterization of Brazilian patients with growth hormone gene deletions. Braz J Med Biol Res, 1998. 31(4): p. 491-7.

7. Arnhold, I.J., et al., Clinical and molecular characterization of a Brazilian patient with Pit-1 deficiency. J Pediatr Endocrinol Metab, 1998. 11(5): p. 623-30. 
8. Cogan, J.D., et al., The PROP1 2-base pair deletion is a common cause of combined pituitary hormone deficiency. J Clin Endocrinol Metab, 1998. 83(9): p. 3346-9.

9. Osorio, M.G., et al., Combined pituitary hormone deficiency caused by a novel mutation of a highly conserved residue (F88S) in the homeodomain of PROP1. J Clin Endocrinol Metab, 2000. 85(8): p. 2779-85.

10. Osorio, M.G., et al., Pituitary magnetic resonance imaging and function in patients with growth hormone deficiency with and without mutations in GHRH-R, GH-1, or PROP-1 genes. J Clin Endocrinol Metab, 2002. 87(11): p. 5076-84.

11. Carvalho, L.R., et al., A homozygous mutation in HESX1 is associated with evolving hypopituitarism due to impaired repressor-corepressor interaction. J Clin Invest, 2003. 112(8): p. 1192-201.

12. Abrão, M.G., et al., Combined pituitary hormone deficiency (CPHD) due to a complete PROP1 deletion. Clin Endocrinol (Oxf), 2006. 65(3): p. 294-300.

13. Melo, M.E., et al., Hormonal, pituitary magnetic resonance, LHX4 and HESX1 evaluation in patients with hypopituitarism and ectopic posterior pituitary lobe. Clin Endocrinol (Oxf), 2007.66(1): p. 95-102.

14. Rocha, M.G., et al., High prevalence of pituitary magnetic resonance abnormalities and gene mutations in a cohort of Brazilian children with growth hormone deficiency and response to treatment. J Pediatr Endocrinol Metab, 2008. 21(7): p. 673-80.

15. Costalonga, E.F., et al., The -202 A allele of insulin-like growth factor binding protein-3 (IGFBP3) promoter polymorphism is associated with higher IGFBP-3 serum levels and better growth response to growth hormone 
treatment in patients with severe growth hormone deficiency. J Clin Endocrinol Metab, 2009. 94(2): p. 588-95.

16. França, M.M., et al., Novel heterozygous nonsense GLI2 mutations in patients with hypopituitarism and ectopic posterior pituitary lobe without holoprosencephaly. J Clin Endocrinol Metab, 2010. 95(11): p. E384-91.

17. Alatzoglou, K.S., et al., Increased transactivation associated with SOX3 polyalanine tract deletion in a patient with hypopituitarism. J Clin Endocrinol Metab, 2011. 96(4): p. E685-90.

18. Costalonga, E.F., et al., Growth hormone pharmacogenetics: the interactive effect of a microsatellite in the IGF1 promoter region with the GHR-exon 3 and -202 A/C IGFBP3 variants on treatment outcomes of children with severe GH deficiency. Pharmacogenomics J, 2012. 12(5): p. 439-45.

19. Pugliese-Pires, P.N., et al., Novel inactivating mutations in the GH secretagogue receptor gene in patients with constitutional delay of growth and puberty. Eur J Endocrinol, 2011. 165(2): p. 233-41.

20. França, M.M., et al., Absence of GH-releasing hormone (GHRH) mutations in selected patients with isolated GH deficiency. J Clin Endocrinol Metab, 2011. 96(9): p. E1457-60.

21. Braz, A.F., et al., The interactive effect of GHR-exon 3 and -202 A/C IGFBP3 polymorphisms on rhGH responsiveness and treatment outcomes in patients with Turner syndrome. J Clin Endocrinol Metab, 2012. 97(4): p. E671-7.

22. França, M.M. and I.J. Arnhold, Clarification of intellectual abilities in patients with GLI2 mutations cited by Kevelam et al., 2012 Am J Med Genet Part A. Am J Med Genet A, 2012. 158A(6): p. 1519. 
23. França, M.M., et al., Relatively high frequency of non-synonymous GLI2 variants in patients with congenital hypopituitarism without holoprosencephaly. Clin Endocrinol (Oxf), 2013. 78(4): p. 551-7.

24. Marui, S., et al., GH-releasing hormone receptor gene: a novel splicedisrupting mutation and study of founder effects. Horm Res Paediatr, 2012. 78(3): p. 165-72.

25. Braz, A.F., et al., Genetic predictors of long-term response to growth hormone (GH) therapy in children with GH deficiency and Turner syndrome: the influence of a SOCS2 polymorphism. J Clin Endocrinol Metab, 2014. 99(9): p. E1808-13.

26. Lido, A.C., et al., Autosomal recessive form of isolated growth hormone deficiency is more frequent than the autosomal dominant form in a Brazilian cohort. Growth Horm IGF Res, 2014. 24(5): p. 180-6.

27. Otto, A.P., et al., Frequent development of combined pituitary hormone deficiency in patients initially diagnosed as isolated growth hormone deficiency: a long term follow-up of patients from a single center. Pituitary, 2015. 18(4): p. 561-7.

28. Correa, F.A., et al., FGFR1 and PROKR2 rare variants found in patients with combined pituitary hormone deficiencies. Endocr Connect, 2015. 4(2): p. 100-7.

29. Arnhold, I.J., et al., Role of GLI2 in hypopituitarism phenotype. J Mol Endocrinol, 2015. 54(3): p. R141-50.

30. Dusatkova, P., et al., Genesis of two most prevalent PROP1 gene variants causing combined pituitary hormone deficiency in 21 populations. Eur J Hum Genet, 2016. 24(3): p. 415-20. 
31. Fang, Q., et al., HESX1 mutations in patients with congenital hypopituitarism: variable phenotypes with the same genotype. Clin Endocrinol (Oxf), 2016. 85(3): p. 408-14.

32. Madeira, J.L., et al., $A$ homozygous point mutation in the GH1 promoter (c.$223 C>T$ ) leads to reduced GH1 expression in siblings with isolated GH deficiency (IGHD). Eur J Endocrinol, 2016. 175(2): p. K7-k15.

33. Madeira, J.L.O., et al., Molecular Analysis of Brazilian Patients with Combined Pituitary Hormone Deficiency and Orthotopic Posterior Pituitary Lobe Reveals Eight Different PROP1 Alterations with Three Novel Mutations. Clin Endocrinol (Oxf), 2017.

34. Correa, F.A., et al., Pathogenic copy number variants in patients with congenital hypopituitarism associated with complex phenotypes. Clin Endocrinol (Oxf), 2018. 88(3): p. 425-431.

35. Correa, F.A., et al., Growth hormone deficiency with advanced bone age: phenotypic interaction between GHRH receptor and CYP21A2 mutations diagnosed by sanger and whole exome sequencing. Arch Endocrinol Metab, 2017. 61(6): p. 633-636.

36. Correa, F.A., et al., Combined pituitary hormone deficiency caused by PROP1 mutations: update 20 years post-discovery. Arch Endocrinol Metab, 2019. 63(2): p. 167-174.

37. Metzker, M.L., Sequencing technologies - the next generation. Nat Rev Genet, 2010.11(1): p. 31-46.

38. Gregory, L.C. and M.T. Dattani, Pituitary Disorders of Childhood: Diagnosis and Clinical Management, ed. L. Poretsky. 2019: Human Press. 
39. Rizzoti, K., Genetic regulation of murine pituitary development. J Mol Endocrinol, 2015. 54(2): p. R55-73.

40. Dateki, S., et al., Heterozygous orthodenticle homeobox 2 mutations are associated with variable pituitary phenotype. J Clin Endocrinol Metab, 2010. 95(2): p. 756-64.

41. Ragge, N.K., et al., Heterozygous mutations of OTX2 cause severe ocular malformations. Am J Hum Genet, 2005. 76(6): p. 1008-22.

42. Dattani, M.T., et al., Mutations in the homeobox gene HESX1/Hesx1 associated with septo-optic dysplasia in human and mouse. Nat Genet, 1998. 19(2): p. 125-33.

43. Villavicencio, E.H., D.O. Walterhouse, and P.M. Iannaccone, The sonic hedgehog-patched-gli pathway in human development and disease. Am J Hum Genet, 2000. 67(5): p. 1047-54.

44. Sornson, M.W., et al., Pituitary lineage determination by the Prophet of Pit1 homeodomain factor defective in Ames dwarfism. Nature, 1996. 384(6607): p. 327-33.

45. Phillips, J.A. and J.D. Cogan, Genetic basis of endocrine disease. 6. Molecular basis of familial human growth hormone deficiency. J Clin Endocrinol Metab, 1994. 78(1): p. 11-6.

46. Sobrier, M.L., et al., Functional characterization of a human POU1F1 mutation associated with isolated growth hormone deficiency: a novel etiology for IGHD. Hum Mol Genet, 2016. 25(3): p. 472-83.

47. Sizonenko and P.C, Diagnosis and management of growth hormone deficiency in childhood and adolescence. 2001, Growth Horm IGF Res. 
48. Alatzoglou, K.S., et al., Expanding the spectrum of mutations in GH1 and GHRHR: genetic screening in a large cohort of patients with congenital isolated growth hormone deficiency. J Clin Endocrinol Metab, 2009. 94(9): p. 3191-9.

49. Sun, Y., et al., Ghrelin stimulation of growth hormone release and appetite is mediated through the growth hormone secretagogue receptor. Proc Natl Acad Sci U S A, 2004. 101(13): p. 4679-84.

50. Phillips, J.A., et al., Molecular basis for familial isolated growth hormone deficiency. Proc Natl Acad Sci U S A, 1981. 78(10): p. 6372-5.

51. Mullis, P.E., J. Deladoëy, and P.S. Dannies, Molecular and cellular basis of isolated dominant-negative growth hormone deficiency, IGHD type II: insights on the secretory pathway of peptide hormones. Horm Res, 2002. 58(2): p. 53-66.

52. Salvatori, R., et al., Familial dwarfism due to a novel mutation of the growth hormone-releasing hormone receptor gene. J Clin Endocrinol Metab, 1999. 84(3): p. 917-23.

53. Lindsay, R., et al., Utah Growth Study: growth standards and the prevalence of growth hormone deficiency. J Pediatr, 1994. 125(1): p. 29-35.

54. Wood, A.R., et al., Defining the role of common variation in the genomic and biological architecture of adult human height. Nat Genet, 2014. 46(11): p. 1173-86.

55. Webb, E.A., et al., ARNT2 mutation causes hypopituitarism, post-natal microcephaly, visual and renal anomalies. Brain, 2013. 136(Pt 10): p. 3096-105. 
56. BM, B., Investigação da Baixa Estatura: do Fenótipo ao Genótipo 2012, 1a. ed. Atheneu: v. I. 175p.

57. Blankenberg, D., et al., Manipulation of FASTQ data with Galaxy. Bioinformatics, 2010. 26(14): p. 1783-5.

58. Li, H. and R. Durbin, Fast and accurate short read alignment with BurrowsWheeler transform. Bioinformatics, 2009. 25(14): p. 1754-60.

59. Li, J., et al., CONTRA: copy number analysis for targeted resequencing. Bioinformatics, 2012. 28(10): p. 1307-13.

60. Naslavsky, M.S., et al., Exomic variants of an elderly cohort of Brazilians in the ABraOM database. Hum Mutat, 2017. 38(7): p. 751-763.

61. Quang, D., Y. Chen, and X. Xie, DANN: a deep learning approach for annotating the pathogenicity of genetic variants. Bioinformatics, 2015. 31(5): p. 761-3.

62. Raimondi, D., et al., DEOGEN2: prediction and interactive visualization of single amino acid variant deleteriousness in human proteins. Nucleic Acids Res, 2017. 45(W1): p. W201-W206.

63. Ionita-Laza, I., et al., A spectral approach integrating functional genomic annotations for coding and noncoding variants. Nat Genet, 2016. 48(2): p. 214-20.

64. Shihab, H.A., et al., Predicting the functional, molecular, and phenotypic consequences of amino acid substitutions using hidden Markov models. Hum Mutat, 2013. 34(1): p. 57-65. 
65. Davydov, E.V., et al., Identifying a high fraction of the human genome to be under selective constraint using GERP++. PLoS Comput Biol, 2010. 6(12): p. e1001025.

66. Chun, S. and J.C. Fay, Identification of deleterious mutations within three human genomes. Genome Res, 2009. 19(9): p. 1553-61.

67. Reva, B., Y. Antipin, and C. Sander, Predicting the functional impact of protein mutations: application to cancer genomics. Nucleic Acids Res, 2011. 39(17): p. e118.

68. Schwarz, J.M., et al., MutationTaster evaluates disease-causing potential of sequence alterations. Nat Methods, 2010. 7(8): p. 575-6.

69. Pejaver, V., S.D. Mooney, and P. Radivojac, Missense variant pathogenicity predictors generalize well across a range of function-specific prediction challenges. Hum Mutat, 2017. 38(9): p. 1092-1108.

70. Choi, Y., et al., Predicting the functional effect of amino acid substitutions and indels. PLoS One, 2012. 7(10): p. e46688.

71. Ioannidis, N.M., et al., REVEL: An Ensemble Method for Predicting the Pathogenicity of Rare Missense Variants. Am J Hum Genet, 2016. 99(4): p. 877-885.

72. Ng, P.C. and S. Henikoff, Predicting deleterious amino acid substitutions. Genome Res, 2001. 11(5): p. 863-74.

73. Dong, C., et al., Comparison and integration of deleteriousness prediction methods for nonsynonymous SNVs in whole exome sequencing studies. Hum Mol Genet, 2015. 24(8): p. 2125-37. 
74. Jian, X. and X. Liu, In Silico Prediction of Deleteriousness for Nonsynonymous and Splice-Altering Single Nucleotide Variants in the Human Genome. Methods Mol Biol, 2017. 1498: p. 191-197.

75. Desmet, F.O., et al., Human Splicing Finder: an online bioinformatics tool to predict splicing signals. Nucleic Acids Res, 2009. 37(9): p. e67.

76. Brunak, S., J. Engelbrecht, and S. Knudsen, Prediction of human mRNA donor and acceptor sites from the DNA sequence. J Mol Biol, 1991. 220(1): p. $49-65$.

77. Böttner, A., et al., PROP1 mutations cause progressive deterioration of anterior pituitary function including adrenal insufficiency: a longitudinal analysis. J Clin Endocrinol Metab, 2004. 89(10): p. 5256-65.

78. Pantel, J., et al., Recessive isolated growth hormone deficiency and mutations in the ghrelin receptor. J Clin Endocrinol Metab, 2009. 94(11): p. 4334-41.

79. Gripp, K.W., et al., Mutations in TGIF cause holoprosencephaly and link NODAL signalling to human neural axis determination. Nat Genet, 2000. 25(2): p. 205-8.

80. Tatsi, C., et al., Pituitary stalk interruption syndrome and isolated pituitary hypoplasia may be caused by mutations in holoprosencephaly-related genes. J Clin Endocrinol Metab, 2013. 98(4): p. E779-84.

81. Pérez Millán, M.I., et al., Next generation sequencing panel based on single molecule molecular inversion probes for detecting genetic variants in children with hypopituitarism. Mol Genet Genomic Med, 2018.

82. Wang, S.R., et al., Large-scale pooled next-generation sequencing of 1077 genes to identify genetic causes of short stature. J Clin Endocrinol Metab, 2013. 98(8): p. E1428-37. 
83. Hauer, N.N., et al., Clinical relevance of systematic phenotyping and exome sequencing in patients with short stature. Genet Med, 2018. 20(6): p. 630638. 